NBER WORKING PAPER SERIES

\title{
THE ASYMMETRY IN RESPONSIBLE INVESTING PREFERENCES
}

\author{
Jacquelyn Humphrey \\ Shimon Kogan \\ Jacob Sagi \\ Laura Starks \\ Working Paper 29288 \\ http://www.nber.org/papers/w29288 \\ NATIONAL BUREAU OF ECONOMIC RESEARCH \\ 1050 Massachusetts Avenue \\ Cambridge, MA 02138 \\ September 2021
}

The authors thank Rob Bauer, Peter Bossaerts, Shaun Davies, Barry Oliver, Sebastien Pouget, Saphira Rekker, Paul Smeets, Gabby Walters, Paul Yoo, and participants at the Inaugural Behavioral, Biological, and Experimental Economics conference, Penn State University, the Principles for Responsible Investment Academic Network conference and seminars at the Financial Research Network, University of Texas at Austin, Villanova University, Victoria University of Wellington, University of Geneva and University of Woollongong for helpful comments. The authors are grateful to Terry Pan (Zheyao), Lee Seltzer, and Mitch Towner for research assistance; Larissa Garcia, Matt Pearsall, Jacob West and their team of assistants for lab assistance; and Alan McCrystal, Alex Cameron, and Paige Ottmar for programming assistance. The views expressed herein are those of the authors and do not necessarily reflect the views of the National Bureau of Economic Research.

NBER working papers are circulated for discussion and comment purposes. They have not been peer-reviewed or been subject to the review by the NBER Board of Directors that accompanies official NBER publications.

(C) 2021 by Jacquelyn Humphrey, Shimon Kogan, Jacob Sagi, and Laura Starks. All rights reserved. Short sections of text, not to exceed two paragraphs, may be quoted without explicit permission provided that full credit, including $(\odot$ notice, is given to the source. 
The Asymmetry in Responsible Investing Preferences

Jacquelyn Humphrey, Shimon Kogan, Jacob Sagi, and Laura Starks

NBER Working Paper No. 29288

September 2021

JEL No. C91,G11,G41

\begin{abstract}
$\underline{\text { ABSTRACT }}$
We design an experiment to understand how social preferences affect investment decisions through stock allocations and probability assessments. The major preference channel is asymmetric in social outcomes - although negative and positive responsible investment (RI) externalities have the same magnitudes, negative externalities have greater impact on investment choices. The effect is persistent, but heterogenous. We also find asymmetries in belief formation and learning constitute a secondary channel. Overall, our results are consistent with important stylized empirical facts and the predictions of recent RI theories that social preferences lead to different investment choices, but our analyses also suggest important future modeling directions.

Jacquelyn Humphrey

The University of Queensland

Australia

j.humphrey@business.uq.edu.au

Shimon Kogan

University of Pennsylvania

skogan@upenn.edu

Jacob Sagi

Kenan-Flagler Business School

UNC Chapel Hill

CB \#3490

Chapell Hill, NC 27599-3490

Jacob_Sagi@Kenan-Flagler.unc.edu

Laura Starks

McCombs School of Business

University of Texas at Austin

2110 Speedway

Austin, TX 78712

and NBER

laura.starks@mccombs.utexas.edu
\end{abstract}




\section{Introduction}

In response to demand from their clients, institutional investors increasingly offer responsible investment (RI) products, attracting attention from regulators, practitioners, and academics. The growth of this approach, also termed environmental, social and governance (ESG) or sustainable and responsible investing (SRI), has arguably been driven in part by societal expectations arising from individuals’ preferences. In particular, the products are viewed as a response to anticipated demand from millennials, who are expected to receive large transfers of wealth from baby boomers in coming years. ${ }^{1}$ The explosive growth in responsible investing has given rise to a growing theoretical literature for both asset pricing and firms' social responsibility that relies on nonpecuniary utility functions (e.g., Heinkel, Kraus and Zechner 2001; Chowdhry, Davies and Waters 2019; Baker, Hollifield and Osambela 2020; Oehmke and Opp 2020; Pastor, Stambaugh and Taylor 2021; Pedersen, Fitzgibbons and Pomorski 2021; Goldstein, Kopytov, Shen, and Xiang 2021). In all of these studies, the authors assume that investors gain utility from aligning their investments with their social values; for example, by avoiding firms with unethical products or poor environmental conduct. The assumption of nonfinancial considerations is backed, to some extent, by empirical and experimental evidence that suggests some investors are willing to forgo returns in order to achieve social goals. ${ }^{2}$

There exists little evidence, however, providing microfoundations for the nonpecuniary utility assumptions used in existing models. That is, we still lack an understanding of key elements driving an investor's decision-making process. This is an important gap in the literature because models shape our growing understanding of RI-related market phenomena. Do nonpecuniary preferences primarily arise from tastes for social outcomes? Do social externalities additionally distort belief formation? Does the impact of these channels vary with

\footnotetext{
${ }^{1}$ See, for example, https://pewrsr.ch/2Op4i3b; https://go.ey.com/2XvjCiP; and https://bit.ly/2O1r5mS.

2 See, for example, Reidl and Smeets (2017), Hartzmark and Sussman (2019), Barber, Morse and Yasuda (2021), Bauer, Ruof, and Smeets (2021), and Geczy, Jeffers, Musto and Tucker (2021).
} 
the sign of the externality (i.e., negative versus positive social externalities)? Are nonpecuniary social preferences broadly distributed across individuals or concentrated among a few? The answers to these questions carry implications for the equilibrium behavior of individuals and firms. If, for instance, ESG perceptions work mostly by impacting belief formation (how investors process information), a firm with a low ESG score might do equally well by increasing its transparency (i.e., reducing the scope for distorted beliefs) than by improving its underlying ESG policies. This would not be the case if, on the other hand, profits earned by low ESG scoring firms are widely perceived as somehow less valuable. Correspondingly, if perceptions of negative social externalities are much more powerful in influencing investors’ choices than perceptions of positive externalities, firms seeking to improve their cost of capital might be made better off by reducing activities with negative social outcomes (e.g., shut down coal plants) rather than increasing activities with positive social outcomes (e.g., invest in clean energy R\&D).

In addition to the increase in theoretical literature on the topic, there also exists a growing number of recent empirical papers seeking to document the causal effect of RI on investors' portfolio choices. Riedl and Smeets (2017) and Hartzmark and Sussman (2019) both examine how retail investors' mutual fund holdings are affected by RI, the former combining administrative account-level data from a large Dutch mutual fund company with survey data, while the latter study complements a natural field experiment resulting from Morningstar's introduction of sustainability ratings with a lab experiment. Both studies conclude that RI has strong, causal effects on the demand for mutual funds, although they argue that these effects arise through different channels. Riedl and Smeets (2017) suggest that investor behavior is not driven by distorted beliefs about the prospects of the firms producing the externalities while Hartzmark and Sussman (2019) find that investors attribute higher prospects to firms with positive RI scores. This highlights the difficulty of controlling for beliefs in field data and, 
importantly, controlling for the magnitude of externalities when comparing positive ("good firms”) with negative (“bad firms”).

In this paper we shed light on these questions through an experimental setting in which we control for investors' information sets and test the relationship between social preferences and investment decisions. In our experimental design, a participant's investment decisions impose externalities on nonprofit organizations (“nonprofits”) focusing on social challenges for which subjects exhibit affinity. If they are so disposed, participants have the opportunity to integrate their RI preferences with an investment objective of optimizing risk-return tradeoffs. Our experimental design unbundles possible channels through which responsible investing acts at the individual level. Specifically, we separately examine whether and how RI concerns (i) distort individuals' subjective beliefs formed through learning from investment outcomes, and (ii) impact their risk attitudes. ${ }^{3}$ Although we find evidence supporting the presence of both channels, by far the most important is the impact of negative social outcomes on risk attitudes. This result is reminiscent of outcome asymmetries in other domains, e.g., loss aversion and prospect theory (Kahneman and Tversky 1979). Our findings have significant implications for modeling and understanding some key empirical stylized facts. For example, while previous evidence shows a discount for sin (shunned) stocks, evidence of a premium for angel stocks or green bonds is, at best, mixed (Hong and Kacperczyk 2009, Statman and Glushkov, 2009, Larcker and Watts, 2020, Flammer 2021). In addition, to disentangle RI channels for decision making, we are able to estimate the strength and prevalence of RI influences on investment across subjects: Roughly half of our subjects might be expected to reduce their allocation to a lucrative risky investment by nearly $50 \%$ if that investment were linked to negative social

\footnotetext{
${ }^{3}$ We define "risk attitudes" as the probability weighting of outcome utility. Importantly, this definition fixes the perceived probability and in that sense controls for deviations from optimal (in this case, Bayesian) belief formation. We note that while non-neutral risk attitudes depend on outcome utility (e.g., as under Expected Utility), they may also arise through non-linear probability weightings of outcome utility (e.g., Weighted Utility, Rank-dependent Utility, Cumulative Prospect Theory, and other models - see Starmer, 2000, for a review).
} 
externalities. The impact of positive externalities pales by comparison. The type, magnitude, and pervasiveness of the effects we identify can be readily incorporated into the modeling, and therefore equilibrium consequences, of RI attitudes.

In our experiment, which is adapted for an RI framework from Kuhnen's (2015) experiment, subjects receive an endowment to allocate between a risky stock and cash over multiple rounds. The stock's returns are binary (can double or halve in value) with the probability of the high outcome being fixed but unknown to subjects. Throughout, the subjects are incentivized to learn and report their beliefs about the stock's prospects. To study how RI considerations distort beliefs and risky allocations relative to a neutral benchmark, we link payoffs from the stock allocation to payments that address social causes. In particular, subjects select which causes and nonprofits they care most about, pertaining to animal welfare, environment, refugees, poverty, human trafficking and gender discrimination. We then link the investment outcomes to the payments the experimenters make to the preferred nonprofits. Significantly, payments to the nonprofits do not come out of subjects' payoffs or endowments but are furnished by the experimenters. Thus, "neoclassical” investors - those who care only about their own payoffs when making investment decisions - would be insensitive to any link with a social cause (in contrast to the investors with nonpecuniary preferences).

The design incorporates three treatments based on the sign of the linkage between subjects’ payoffs from the stock investment and payments to preferred nonprofits. In the Neutral treatment, the two are unrelated (there are no payments to nonprofits). In the Positive (Negative) treatment, payoffs from the stock investment are matched by equal contributions (deductions) to the preferred cause. ${ }^{4}$ The more the subject earns from their stock investment, everything else equal, the more the nonprofit receives in the Positive treatment, but the less the

\footnotetext{
4 The Neutral treatment is always presented first to the subjects, prior to any discussion of social issues. The order of the Negative and Positive treatments are randomized across subjects to control for priming effects in average results.
} 
nonprofit receives in the Negative treatment. In the Positive and Negative treatments, a subject weighs how an allocation to the risky asset will impact both personal gain and the social goals with which they are most aligned.

This design affords two important advantages. The first advantage is in creating a clear null hypothesis: Under neoclassical preference assumptions, allocations and beliefs should be similar across the different treatments. In particular, we are able to draw causal RI inferences because the design rules out common alternative (pecuniary) reasons for RI preferences. Such reasons include the possibility that a stock aligned with one's social preferences can provide higher returns (for example, due to gains from product differentiation; e.g., Albuquerque, et al., 2019), lower risk (due to avoidance of risk; e.g., Hoepner, et al, 2021) or lower returns (for example, due to a constrained investment opportunity set; e.g., Geczy, Stambaugh and Levine, 2021; Fabozzi, Ma and Oliphant, 2008). The second important advantage of our design lies in its ability to keep the magnitude of the externalities constant across treatments. Thus, we can compare behavior not just against the Neutral treatment but also between the Positive and Negative treatments in a way that controls for the nature of the external cause. The design mimics a secondary market environment facing atomistic investors whose individual actions have insignificant impact on the firms being traded. The treatments only distort investors' nonpecuniary motives and, in so doing, allow us to study how such preferences are incorporated into an investment context.

The experiment generates round-by-round data on individuals' elicited beliefs over stock payoffs as well as data on their stock allocation choices. We document a statistically strong impact from negative RI externalities on both reported beliefs and allocation decisions relative to a baseline provided by the Neutral treatment. The influence is economically pronounced over risk attitudes (roughly a 30\% reduction in average allocation across subjects), though much less so over beliefs formation. In stark contrast, we find little internalization of positive 
RI externalities on either beliefs or risk attitudes. Data from the Positive treatment resembles data from the Neutral treatment. This is especially surprising given that a simple charitablegiving motive, prevalent in practice and in experimental economics, would lead one to expect a difference between the Neutral and Positive treatments. Thus, while an investment context may mask or muddle charitable-giving behavior, it is overwhelmed by negative RI stimulus.

The experimental data allow us to estimate for each subject an allocation "response" function to subjective probability that, in turn, can be used to estimate the strength and pervasiveness of RI attitudes in our subject pool. Specifically, expected responses at the subject level can be described as a mixture of normal distributions. Each such normal distribution can be viewed as a single homogeneous sub-population. In doing so, we find significant heterogeneity across subjects' RI sensitivities to negative but not positive externalities. While the vast majority of subject preferences in response to positive social externalities appear to come from a single homogeneous sub-population that is only weakly attuned to positive RI stimulus, the negative externality splits the subject population into two roughly-equal subpopulations: One weakly and one strongly sensitive to the negative RI stimulus. The latter would be expected to reduce their allocation to the risky asset in the experiment by an average of $50 \%$. The heterogeneity we document is a quantitatively critical component of the theoretical literature on the equilibrium effects of responsible investing (Heinkel, Kraus, and Zechner, 2001; Luo and Balvers 2017; Baker, Hollifield and Osambela 2020; Oehmke and Opp 2020; Goldstein, Kopytov, Shen, and Xiang 2021; Pastor, Stambaugh and Taylor, 2021; Pedersen, Fitzgibbons and Pomorski, 2021). It is also consistent with the empirical and experimental literature (e.g., Bauer, Rouf and Smeets, 2021; Bonnefon et al., 2019; Brodback, Guenster and Mezger, 2019), but shows the asymmetry in individuals’ responses. 
The paper is further organized as follows: Section 2 details the contribution to the literature, Section 3 outlines the experiment, Section 4 reports the details of our analyses, and Section 5 concludes.

\section{Contribution to the Literature}

Our main findings concern the asymmetric impact of negative RI externalities on belief formation and risk attitudes, and on the distribution of sensitivities to RI externalities in our sample of subjects. Each of these findings, in turn, may have significant implications for distinct branches of the RI literature. Taken together, our findings point towards a paradigm that can better inform the modeling of RI phenomena.

\subsection{Asymmetry in RI attitudes}

Our findings resonate with a number of empirical stylized facts. For example, our asymmetric results on preferences over negative versus positive externalities are consistent with Krueger’s (2015) findings that market reactions to negative ESG information about firms are greater, in absolute magnitude, than market reactions to positive ESG news. The results also conform to what we observe in practice in the RI market where the avoidance of negative externalities is clearly seen through the prevalence of negative screening in RI products. Indeed, the roots of responsible investment derive from screening out investments in order to avoid certain products or corporate behaviors that are viewed as harmful. ${ }^{5}$

Although much of RI has evolved to include positive tilting toward companies that have better ESG practices, negative screening remains pervasive as many investors wish to avoid seeming (to others or themselves) to be complicit by holding stocks that have harmful products or objectionable corporate behavior. Examples of such decisions include avoidance of coal

\footnotetext{
${ }^{5}$ See Renneboog, ter Horst and Zhang (2008b) for a description of the early responsible investors such as the Quakers during the 1800s who did not want gains derived from weapons or slavery.
} 
products (or even fossil fuels in general), palm oil (because of destruction of forests), tobacco, alcohol, and companies that have human rights abuses or that violate labor rights. An oftenfollowed model of this investment approach is the Norwegian sovereign wealth fund (the Government Pension Fund Global) which invests sustainably but also excludes companies that they believe do not meet their ethical norms. ${ }^{6}$

Negative screening is also a predominant strategy in the United States as detailed in surveys of RI institutional investors. ${ }^{7}$ For example, of the 86 U.S. investment managers who reported their screening technologies to the PRI, 91\% use some type of negative screening strategy. In fact, 33\% use only negative screening while 58\% use negative screening combined with some form of positive screening. ${ }^{8}$ Similarly, a US SIF survey finds that $69 \%$ of managers use negative screening in their investment decisions (US SIF, 2020). Finally, similar to our results under a different experimental setting, Chew and Li (2021) find strong evidence for asymmetry in sin stock aversion versus virtue stock affinity in their experimental study, which they model by appealing to the literature on source-dependent risk aversion.

\subsection{The role of distorted beliefs}

Importantly, our study points to another potential (albeit weaker) channel impacting asset markets by RI investors. If the ability of individuals to infer the likelihood of outcomes is impacted by their RI preferences as our results imply, asset prices will be affected beyond what is suggested in earlier theoretical work that focuses only on the impact of tastes on allocations. Here too, if a sufficiently large proportion of RI investors in the economy is sensitive to RI, beyond the asset allocation distortions, distortions could arise from the effective presence of

\footnotetext{
${ }^{6}$ https://www.nbim.no/en/the-fund/responsible-investment/.

7 The PRI is an organization originally founded by the United Nations to support responsible investing. Similarly, the US SIF: The Forum for Sustainable and Responsible Investment seeks to advance sustainable, responsible and impact investing across all asset classes.

${ }^{8}$ We thank the PRI for providing us with 2018 data. The PRI has not reviewed the methodology applied to, use of, or conclusions drawn from this data.
} 
“pessimistic” investors (see, for example, Scheinkman and Xiong, 2003). Relatedly, we note that RI preferences in the model of Pastor, Stambaugh and Taylor (2021), employing CARA utility investors, can be recast as one in which investors’ beliefs are distorted by RI influences. Because not all models have this feature, it seems useful to disentangle the beliefs and the riskattitude RI channels. Our results provide empirical guidance on how this may be done.

\subsection{Pecuniary alignment}

Our study is related to earlier work in RI on returns, flows and investor motivations. An alternative, although not mutually exclusive, conceptual explanation for the incorporation of social preferences into investment decision-making relies on the idea that social preferences can affect investment decisions simply because they serve as a proxy for value-relevant information or risk. That is, social preferences conform to financial considerations because they enhance performance or reduce risk. Some supporting empirical evidence suggests that investors expect their social preferences to be aligned with higher returns or lower risks (e.g., Dimson, Karakas and Li, 2015, 2021; Hoepner, et al, 2021; Barber, Morse and Yasuda, 2021; Krueger, Sautner and Starks, 2020; Stroebel and Wurgler, 2021).

The question of whether responsible investing generates outperformance or underperformance has long been a heavily debated question, particularly with regard to causality. Theoretical arguments suggest companies that exhibit more social responsibility should outperform. ${ }^{9}$ This has often been tested using SRI funds or the performance of firms judged to have high Corporate Social Responsibility (CSR) attributes. These studies have used short-term market reactions, valuation levels and long-run stock returns, but have come to disparate conclusions as to the value of such investment strategies. ${ }^{10}$ In a meta-analysis of over

\footnotetext{
${ }^{9}$ See, for example, Benabou and Tirole (2010); Baron (2007, 2008); and Albuquerque, Koskinen, and Zhang (2019).

${ }^{10}$ From some of the earliest research (e.g., Hamilton, Jo and Statman, 1993, and Guerard, 1997, both of which found no significant difference in the returns on SRI funds or socially screened universes), studies have varied
} 
2,000 published empirical academic studies (in fields such as management science, finance, and economics), Friede, Busch and Bassen (2015) report that for those studies that examine return performance of firms, about 57\% document a significantly positive relationship with CSR strategies and only 5.8\% a significantly negative relationship, with the rest being either neutral or mixed in their results. In contrast, in studies that employ portfolios (such as SRI mutual funds or indices), the authors find that $15.5 \%$ document a significantly positive relationship with SRI strategies, while the majority of the studies find either no significant difference in returns or mixed results. Our work contributes to that literature by showing a strong link between investors' tastes (rather than outcomes) and their allocations, and that this link is somewhat asymmetric in being more strongly driven by negative RI association. This is consistent with the stronger evidence of shunned stock outperformance (e.g., Hong and Kacperczyk, 2009; Statman and Glushkov, 2009), as compared to the mixed evidence found for strategies favoring SRI funds and CSR firms. Thus, our findings provide a way to interpret the array of evidence documented in a large and growing literature and point a way towards developing new theories.

Substantial work has examined the effects of RI concerns on mutual fund flows. For example, studies have generally found that responsible investing matters for fund flows as the flows into SRI/ESG funds tend to be stickier and have less performance sensitivity. ${ }^{11}$ Our work contributes by showing experimentally how investor attitudes toward RI information affect allocations, holding constant the return distribution. This has a natural analogy to the mutual fund context in terms of fund flows. Further, our results showing the asymmetry in how

in their conclusions as to whether CSR/SRI/ESG attributes add to corporate value and the risk premiums that can arise. See, for example, Statman and Glushkov (2009), Edmans (2011); Humphrey, Lee and Shen (2012); Lins, Servaes and Tamayo (2017); Bolton and Kacperczyk (2021) among many others.

${ }^{11}$ See for example, Bollen (2007), Benson and Humphrey (2008), Renneboog, ter Horst and Zhang (2008a), Bialkowski and Starks (2018), and Hartzmark and Sussman (2019). 
individuals treat "negative” versus "positive” RI externalities are consistent with studies that find fund flows and stock market reactions are more strongly affected by negative RI events. ${ }^{12}$

\subsection{Investor heterogeneity and theoretical RI models}

Our results, particularly the results regarding the effects of negative RI information on investors' asset allocations and beliefs, have important implications for financial markets. As the percentage of RI investors grows in the economy, asset prices are likely to be affected by their allocation choices as has been shown both theoretically and empirically. For example, the RI theory papers cited earlier show that if the proportion of RI investors in the economy is large enough, asset prices will be affected. In addition, Luo and Balvers (2017) demonstrate how shunning of sin stocks would have the effect of driving these stocks' prices lower, which has empirical support in Hong and Kacperczyk (2009), Statman and Glushkov (2009), as well as Chava (2014). Similarly, Fama and French (2007) provide a simple theoretical framework to demonstrate that investor tastes, such as tastes for responsible investing, can distort pricing in asset markets. They show that these distortions in prices could be large under certain circumstances: when investors with particular tastes represent a substantial fraction of invested wealth; when the investors have such tastes for a wide range of assets; when investors' positions vary quite a bit from the market portfolio; and when the returns on the investors' underweighted assets are not highly correlated with the returns on their over-weighted assets. In other words, it is plausible to expect an impact on asset prices when responsible investors represent a substantial percentage of investors in the market. In finding that, ceteris paribus, roughly half of our subject pool would reduce their allocation to an asset with negative RI association, we provide tangible quantitative guidance for modeling and understanding how heterogeneity in investor social preferences may impact markets.

\footnotetext{
${ }^{12}$ See, for example, Krueger (2015); Bialkowski and Starks (2018); Hartzmark and Sussman (2019).
} 


\subsection{Other experimental studies}

Three recent studies, all of which are based on Dutch investors, examine investors' choices of responsible investing strategies. Reidl and Smeets (2017) conclude that intrinsic social preferences and social signaling are the primary motivations and that while financial motivations enter into the decision making, they play a relatively minor role. Brodback, Guenster and Mezger (2019) find a positive link between altruistic values and the relative importance of social responsibility to investors. They also find that the link strengthens under certain conditions: when individuals believe their investments can make a social or environmental impact or when they feel moral obligations regarding their investments. In contrast, the authors also find a link with egoism in that more egoistic investors avoid responsible investing. Lastly, Bauer, Rouf and Smeets (2021) conduct a field experiment in which Dutch pension participants are allowed to vote on whether the pension system should follow three or four of the United Nations Sustainable Development Goals. They conclude that the choice of $66 \%$ of the participants to follow more of the goals, i.e., engage in more responsible investing activities, is based on nonfinancial rather than financial considerations. Whereas these papers seek to answer the question of why investors select into being RI investors, our work shows how the RI information is incorporated into investors' decisions.

Our analysis is complementary to two contemporaneous experimental studies, but the focus and consequently, the experimental design, exhibit key differences. Bonnefon et al. (2019) examine the private valuation assigned by MTurk subjects to direct giving to (or taking from) charities. They find that this private valuation is roughly linear in the small stakes considered. Moreover, private valuations do not significantly depend on whether or not a subject is pivotal to the giving (i.e., whether the amount the charity receives depends on actions taken by the subject). Our design is fundamentally different in that it incorporates and examines 
dimensions of quantity, uncertainty, and learning linked to the RI decision. On the other hand, we do not test for a difference between pivotal and non-pivotal treatments. Whereas both our paper and Bonnefon et al. (2019) provide strong evidence that tastes matter in evaluating RI, they appear to find no evidence for the strong asymmetric results discovered in our setting. ${ }^{13}$

Brodbeck, Guenster and Pouget (2020) also conduct an experiment with charitable donations tied to a financial investment, in this case an initial public offering. They find that individuals have a price premium for social responsibility that also depends on the asset's financial performance. Their focus is on the pricing of the social benefit in combination with the financial performance while our focus is on how the preferences affect beliefs and allocations. Lilkewise, Heeb et. al. (2021) focus on investor's willingness to pay for sustainable investment in an experimental setting. They focus on positive externalities and how willingness-to-pay changes with impact and the choice set.

Finally, we point out that a vast literature exists on "other-regarding behavior," mostly focused on strategic choice problems. ${ }^{14}$ Although gain-loss asymmetry, introduced in Kahneman and Tversky (1979), is one of the most influential and persistent stylized facts in human decision making, the evidence we find for its social preference manifestation appears to be new.

\section{Experimental design}

\subsection{Description of experiment}

The experiment is organized around a basic set of tasks we term a "trial" performed through a computer terminal. ${ }^{15}$ The experiment itself consists of a series of trials, some of which include

\footnotetext{
13 The significantly smaller stakes employed in Bonnefon et al. (2019) for both subjects and charities might serve to mask a difference between the pivotal and non-pivotal treatments, or an asymmetry between the impact of negative versus positive payoffs to the charity.

${ }^{14}$ See Cooper and Kagel (2016) for a review.

${ }^{15}$ Each subject participates in the experiment through a distinct computer terminal, asynchronously and independently of other subjects. We use Qualtrics. Software randomization is independent across subjects.
} 
treatment effects. Before describing the experiment's sequence of events, we detail the mechanics of a single trial.

At the beginning of each trial, participants are informed that a stock in which they can invest during that trial may be one of two types: a high payoff stock that doubles the amount invested with a probability of $2 / 3$ and halves the investment with a probability of $1 / 3$; or a low payoff stock that doubles investment with a probability of $1 / 3$ and halves it with a probability of 2/3. Participants are also informed that the computer randomly selects the stock type at the beginning of the trial, with equal probability, and that the stock's type remains fixed for the duration of the trial. The trial consists of six rounds of investment during which subjects can learn about the stock's type. Although investment payoff outcome is disclosed at the end of each round, the stock type is not disclosed.

Before the first round starts, participants are asked to estimate the probability that they are facing the high payoff stock. The correct answer is $50 \%$ as participants were told that the computer randomly selects the stock type with equal probability. Participants next allocate an endowment of 100 experimental currency units (ECU) between the stock and cash. $^{16} \mathrm{~A}$ snapshot of the initial round allocation screen is displayed in Panel A of Appendix 1. The computer then randomly generates an outcome consistent with the distribution of the stock given its true type, and participants receive a report of the results of their investment round, i.e., whether the stock doubled or halved, as well as the value of their winnings. Having observed whether the stock doubled or halved in the first round, participants are asked to again estimate the probability that the stock is of the high payoff type and to allocate $100 \mathrm{ECU}$ between the stock and cash. This process repeats until six investment rounds are completed. At the end of each round, participants are shown a history of their probability estimates, their stock allocations, the stock outcomes (whether it doubled or halved) and their winnings from each

\footnotetext{
${ }^{16} 100 \mathrm{ECU}$ is equivalent to US\$10.
} 
prior round. Panel B of Appendix 1 depicts a screen capture of what a subject might see after round three of a trial.

To encourage attentiveness, the experiment incorporates prompts asking participants if they are sure of their decisions whenever they appear to violate a monotonicity condition. For example, a prompt appears any time a stock outcome "halves" but a participant increases either the allocation to the stock or the estimated probability that it is a high payoff stock.

We now describe the full sequence of events (and trials). At the start of the experiment, participants are told that they will be taking part in an experiment in decision-making, and their main task will be to choose how to allocate an investment of 100 ECU between a risky stock and cash in each of a set of rounds. Participants are told that the total payout they can expect from the experiment consists of a US\$7 participation fee, plus the total stock and cash payoff from one randomly selected non-practice round, plus US\$1 if the stock-type probability estimate made by the participant in the randomly selected round is within $5 \%$ of the true probability. Participants are also told that, given the stock's history, there is an objectively true probability that the stock is the high payoff type.

Each subject participates in seven trials divided into four blocks. The first block consists of a single practice trial and serves to familiarize participants with the process. The second block consists of two trials that set a baseline we term the Neutral treatment. A subject then participates in two additional treated blocks, each consisting of two trials: a Positive treatment block and a Negative treatment block (in randomly determined order). Because each trial consists of six investment decisions and probability elicitations, excluding the practice trial, we collect 36 observations of allocation decisions and 36 observations of likelihood perceptions, per subject.

Treatment proceeds as follows. Once a participant completes the Neutral block, we elicit their social preferences by asking them to rank six social issues in order of importance. 
The six issues are: animal welfare, environment, refugees, poverty, human trafficking and gender discrimination. Participants then view a screen that describes two nonprofit organizations related to their top ranked social issue. They are asked to select one of the nonprofit organizations to link to their trading outcomes. This process is repeated for the second-ranked social issue. Panel $\mathrm{C}$ of Appendix 1 depicts a snapshot of the social issue decision screens.

Participants subsequently proceed to either the Positive or Negative treatment block (the assignment is random). In the Positive block, participants are told that an amount of money equal to their stock payoff would be donated to a selected nonprofit. In the Negative block, they are told that an amount of money equal to their stock payoff would be deducted from a selected nonprofit's donation account. ${ }^{17}$ It is important to note, as emphasized to the participants, that the amounts donated to (or deducted from) a selected nonprofit would not affect the participant's own gains during the experiment. The nonprofit remains fixed for both trials of a given block, but changes across treatment blocks. Panels D and E of Appendix 1 show the instructions for the Positive and Negative blocks, respectively. Also shown in Panels $\mathrm{D}$ and $\mathrm{E}$ of Appendix 1 is that during each trial, participants receive a report of the amounts to be potentially gained by or deducted from the nonprofit in past investment rounds (this can be compared with the feedback provided in the Neutral block - see Panel B).

The six non-practice trials in the experiment are payoff-equivalent for the subjects regardless of treatment. The only difference across blocks is that investment decisions may determine whether a nonprofit to which the subject exhibits some affinity gains (loses) money in the Positive (Negative) treatments. This allows us to examine the causal impact of treatment

\footnotetext{
${ }^{17}$ We randomize whether the first or second ranked social issue's non-profit is assigned to the Positive or Negative block.
} 
on likelihood perceptions and willingness to invest (i.e., risk attitudes) given a likelihood perception.

\subsection{Description of subjects}

We recruited 160 participants from the University of Texas at Austin (62 identified as male, 97 as female, one did not identify themselves). The age of the participants ranged from 18 to 34 with a median of 20. This age group may merit particular attention because of prevailing interest in the potential effects of millennials on asset markets. During our study period millennials ranged in age from 23 to their mid-30s. Most participants were students at the school, with 50 enrolled in business-related degrees, 39 in natural sciences, 19 in medicine, 16 in engineering, 10 in social sciences, and the remainder in arts/humanities, law, nursing, mathematics and communication. Somewhat surprisingly, demographic variables were not associated with the main effects we identify in the following section and we omit them from our reported analyses.

\section{Empirical results}

\subsection{Overview}

The two dependent variables that we analyze are the participants' allocations (in ECU) to the stock investment and their probability estimates of the stock being of the high payoff type. To analyze the treatment effect on each of these dependent variables we begin with a simple comparison of their average levels across the three treatments (Negative, Neutral, and Positive), causing a single observation for each subject-treatment. This, of course, is the most conservative use of data as it ignores variation among the 12 observations within a subjecttreatment.

In Table 1 we report the participants' allocations in Panel A, showing the differences across treatment conditions in the allocations to the risky stock. On average, subjects allocated 
28.1, 36.7, and 39.0 (all out of 100 ECU) in the Negative, Neutral, and Positive treatments.

Thus, relative to the Neutral treatment, the average allocation to the stock is $23 \%$ lower in the

Negative treatment, but only 6\% higher in the Positive treatment. Moreover, the difference between the Neutral and Negative condition is statistically significant at the $1 \%$ level, while the difference between the Neutral and Positive condition is only marginally significant at the 10\% level (Panel B).

Table 1: Stock Investment Allocations and Probability Estimates

This table reports the means, standard deviations, and ranges of the participants' choices regarding the stock investment allocations in each of the conditions and their estimates of the probability that they were facing a high payoff stock. The table also includes tests for whether the allocations and estimates are different across treatments. Matched sample $t$-test $p$-values are reported, testing for mean differences between treatments (e.g., Negative=Neutral).

Panel A: Stock allocation in ECU

\begin{tabular}{ccccc}
\hline & Negative $(\mathrm{N}=160)$ & Neutral $(\mathrm{N}=160)$ & Positive $(\mathrm{N}=160)$ & Total $(\mathrm{N}=480)$ \\
\hline Mean (SD) & $28.104(17.817)$ & $36.651(20.557)$ & $39.044(21.739)$ & $34.600(20.606)$ \\
Range & $0.000-100.000$ & $4.167-95.833$ & $2.833-100.000$ & $0.000-100.000$ \\
\hline
\end{tabular}

Panel B: $p$-values from matched sample $t$-tests on stock allocation

\begin{tabular}{llll} 
& Negative=Neutral & Negative =Positive & Positive $=$ Neutral \\
\hline Probability & $0.0 \%$ & $0.0 \%$ & $7.1 \%$ \\
\hline
\end{tabular}

Panel C: Probability estimates

\begin{tabular}{ccccc}
\hline & Negative $(\mathrm{N}=160)$ & Neutral $(\mathrm{N}=160)$ & Positive $(\mathrm{N}=160)$ & Total $(\mathrm{N}=480)$ \\
\hline Mean (SD) & $46.713(13.039)$ & $48.976(11.492)$ & $48.618(12.327)$ & $48.102(12.316)$ \\
Range & $9.667-75.917$ & $5.833-77.417$ & $8.833-81.667$ & $5.833-81.667$ \\
\hline
\end{tabular}

Panel D: $p$-values from matched sample $t$-tests on probability estimates

\begin{tabular}{llll} 
& Negative=Neutral & Negative $=$ Positive & Positive $=$ Neutral \\
\hline Probability & $8.8 \%$ & $12.3 \%$ & $76.4 \%$ \\
\hline
\end{tabular}

We also report the average level of the participants' estimates of the probability that the stock is the high payoff type. In comparing Panels $\mathrm{C}$ and $\mathrm{A}$ it is evident that the treatment effects are not as strong for probability estimates as for allocations to the risky stock. Probability estimates are similar at $46.7 \%, 49.0 \%$, and $48.6 \%$ for the Negative, Neutral, and 
Positive treatments, respectively. Testing for the differences in probability estimates across the treatments suggests that only the Negative and the Neutral treatments are (marginally) significantly different (Panel D). There appears to be no significant difference between the probability estimates for the Positive and the Neutral treatments.

Table 1 provides a first glimpse of results that turn out to be robust in the experimental data: Subjects' allocation choices and probability estimates are sensitive to the Negative but not the Positive treatment. Moreover, the sensitivity to the Negative treatment is more pronounced for allocation choices than for probability estimates. While it is not surprising that subjects internalize the negative externalities that their choices impose, it seems quite surprising that the response to Positive externalities is relatively muted. Charitable giving is both prevalent in practice and in experimental economics (e.g., see the metastudy of the Dictator Game in Engel, 2011). Consider that, in our design, any increase in allocation to the risky asset in the Positive treatment is a stochastically dominating improvement for the linked nonprofit. ${ }^{18}$ Conventional wisdom, and intuition, might suggest that a significant number of subjects would therefore allocate more to the stock in the Positive treatment than they might otherwise. The fact that they do not signals that they respond to the investment context in a manner that is different from conventional charitable giving. ${ }^{19}$ The finding that subjects are sensitive to the imposition of negative externalities is remarkable precisely because, in the same context, they are nearly indifferent to charitable giving.

\subsection{Allocations}

Although the allocations are affected by subjective probabilities, the summary statistics provide evidence that RI considerations are affecting allocations to the stock above and beyond what

\footnotetext{
${ }^{18}$ Even if subjects may not recognize this fact in the abstract, they can perceive it in the report we provide (e.g., Panel D, Appendix I) on how their allocations in the Positive treatment translate into outcomes for the nonprofit. ${ }^{19}$ List (2007), for instance, provides examples of contexts that can greatly influence pure charitable-giving motives via the Dictator Game.
} 
can be easily explained by shifts in beliefs alone. To help disentangle the effects, we focus on the allocation decision given subjects' likelihood perceptions, and later separately examine the effects of RI on probability estimates.

Before applying a more structured approach to the data, we filter for weakly rational behavior on the part of the participants. By this we mean that subjects in the Neutral treatment should, on average, exhibit a weakly positive relationship between actual and subjective (i.e., estimated) probabilities that the stock is high payoff, and a weakly positive relationship between subjective probabilities and stock allocations. We interpret violations of these conditions in the Neutral treatment to signify lack of engagement or confusion about the basic experimental tasks. We test for the conditions, at the subject level, using linear regression. Of the 160 subjects, 35 were dropped because they violated one or both of these requirements. It is important to note that this filter is only applied through the Neutral treatment and thus does not implicitly condition on behavior in the main treatment cells of interest - the Positive and Negative conditions. We proceed by analyzing the data from the remaining 125 subjects though it bears emphasizing that we obtain qualitatively similar results without this filter.

Table 1, Panel C, indicates that subjective probabilities in the Negative treatment are below those in the Neutral or Positive treatments. That would be sufficient to predict lower allocations in the Negative treatment. To control for the impact on probability assessment and examine the treatment effects on allocation separately from their effects on beliefs, we pool allocation observations across all rounds based on subjects' reported (i.e., subjective) probability bins as depicted in Figure 1.

A number of suggestive patterns emerge from the plot. First, allocations in the Negative treatment are lower across almost the entire range of subjective probabilities compared with the Neutral or Positive treatments. Second, the effect does not appear to be uniform - instead, the difference between the allocations in the Negative treatment and the other treatments 
appears to increase as subjective probabilities increase. Finally, there appears to be only a marginal treatment effect on allocations when comparing the Positive condition to the Neutral one. ${ }^{20}$ To further quantify these observations, we regress allocations in each round on treatment dummies, the reported subjective probabilities, and interactions between treatment dummies and the reported probabilities. All regressions include subject fixed effects to control for heterogeneity in average allocations across subjects.

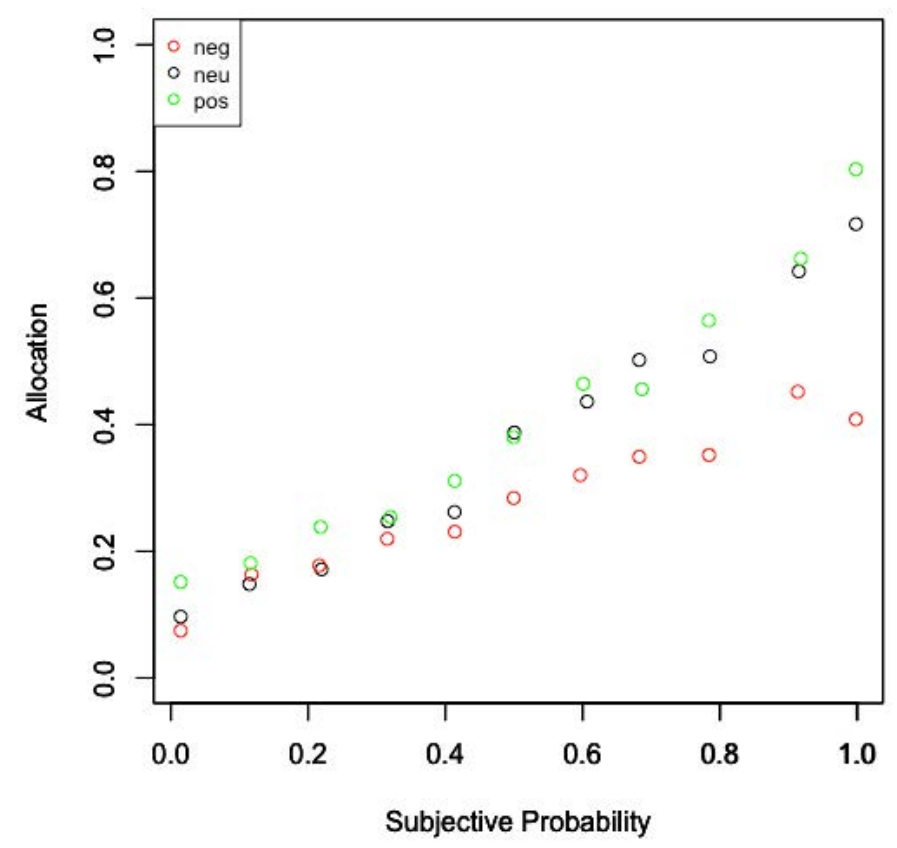

\section{Figure 1: Treatment effects on allocations}

This figure shows the treatment effects on allocation (y-axis), scaled to 0.0-1.0, against subjective probability estimates that the stock is of high type (x-axis). We group observations based on the subjects' reported rather than objective probabilities to control for allocation differences that may arise from different assessments of probabilities.

Table 2 confirms the patterns reported in Table 1 and Figure 1. In regression (1), allocations in the Negative treatment, which are the baseline, are, on average a highly significant 9.6 ECUs lower than in the Neutral treatment. The increase in allocation observed

\footnotetext{
${ }^{20}$ The average Neutral treatment allocation per bin is greater than that of the Positive treatment in only two of eleven plotted bins. Under a 50-50 null (consistent with indifference) between the bin statistics, this is associated with a two-sided $p$-value of $6.6 \%$.
} 
in the Positive treatment is $1.6(=11.2$ - 9.6) ECUs higher than in the Neutral treatment, but the difference is barely significant at the $5 \%$ level. Regression (2) demonstrates that, while there is a strong treatment effect, it does not appear to have a significant constant component (the un-interacted treatment dummies). On the other hand, we find that the response of allocations to probabilities is much lower in the Negative treatment relative to the Neutral treatment, 0.381 vs. 0.589, but there is no significant difference between the Neutral and Positive treatments. This is consistent with a more pronounced allocation reduction in the Negative treatment, relative to the others, as subjective probabilities increase.

\section{Table 2: Stock allocations and probabilities}

The table reports regressions of round-by-round percentage allocations to the stock on reported subjective probabilities ("Prob"), treatment dummies, and interactions between reported probabilities and the treatment dummies. The Negative treatment is the baseline. Standard errors are in parentheses. All regressions include subject fixed effects. The analysis is limited to subjects exhibiting weak rationality in the Neutral treatment (see text).

\begin{tabular}{|l|c|c|}
\hline & $(1)$ & $(2)$ \\
\hline Prob & & $0.381^{* * *}$ \\
\hline \hline Neutral Block Dummy & $0.096^{* * *}$ & $(0.023)$ \\
\hline & $(0.008)$ & $(0.012$ \\
\hline \hline Positive Block Dummy & $0.112^{* * *}$ & 0.018 \\
\hline & $(0.008)$ & $(0.017)$ \\
\hline \hline $\begin{array}{l}\text { Prob x Neutral Block } \\
\text { Dummy }\end{array}$ & & $0.208^{* * *}$ \\
\hline & & $(0.032)$ \\
\hline \hline $\begin{array}{l}\text { Prob x Positive Block } \\
\text { Dummy }\end{array}$ & & $0.182^{* * *}$ \\
\hline & & $(0.033)$ \\
\hline \hline Observations & 4,500 & 4,500 \\
\hline $\mathrm{R}^{2}$ & 0.369 & 0.527 \\
\hline Adjusted R & 0.351 & 0.513 \\
\hline Residual Std. Error & 0.219 & 0.189 \\
\hline
\end{tabular}

Regression (2) in Table 2 may be interpreted as evidence that the negative treatment primarily impacts subjects' risk attitudes (i.e., the sensitivity of allocation to subjective probability). Note that a significant “charitable-giving” motive implies a significant Positive 
Block Dummy coefficient. This is because any additional amount allocated to the stock in the Positive treatment, even when the subjective probability is zero, results in a stochastically dominating distribution to the nonprofit. That said, consistent with the absence of a charitablegiving motive, there exists little evidence that the Positive treatment is associated with a change in risk attitudes.

\subsection{Heterogeneity of treatment effects}

The results so far focus on averaging treatment effects across subjects. There are two important reasons to go beyond that. First, an interpretation of the results in Table 2 in terms of an impact on individual risk attitudes is, at best, indirect because the analysis relies on the average treatment effect across all subjects. Second, as a number of theoretical contributions show (e.g., Heinkel, Kraus, and Zechner, 2001; Pastor, Stambaugh, and Taylor, 2021), the fraction of agents who incorporate social preferences when making investment decisions is a critical determinant of equilibrium outcomes. The primary focus of this subsection is to quantify the heterogeneity of social preferences in the subject pool. We seek to confirm that the average treatment effect primarily arises from an impact on risk attitudes and assess whether it can be attributed to a few subjects with very strong social preferences or whether it is widely prevalent among individuals. To answer these questions, we employ a framework that allows us to parsimoniously capture within subject risk attitudes and treatment-level variations, as well as adjust for potential bias arising from experimental noise and the constraints on the stock allocation.

In a naïve approach we would regress allocations on subjective probabilities for each subject and treatment, but this presents two major challenges. First, a subject-by-subject regression analysis lacks power because we have only twelve decisions for each subject per 
treatment. Second, subject responses reflect experimental error for a variety of reasons. ${ }^{21}$ Because allocations are bounded between 0 and 100 ECU, experimental noise can bias observations away from the bounds and correspondingly bias inferences about individual allocation responses to perceived probabilities. ${ }^{22}$ To address these issues, we adopt a reduced form model relating noisy optimal allocations to subjective probabilities. We then estimate individual-level parameters as random effects. This allows us to efficiently quantify individual risk attitudes as well as attempt to control for edge biases arising from noise.

We begin by noting that most utility models predict an optimal allocation that roughly resembles a sigmoid function of subjective probability. ${ }^{23}$ Consistent with that, we assume that noisy individual allocations, in a given treatment, can be described in reduced form as follows:

$$
E C U_{i}^{T}=a_{i}+b_{i} f\left(\operatorname{Prob}_{i}\right)+e_{i}
$$

where the transformed allocation, $E C U^{T} \in \mathfrak{R}$, is unbounded and related to the allocation choice via the sigmoid transformation,

$$
E C U=100 /\left(1+\exp \left(-E C U^{T}\right)\right) .
$$

In Equation (1), $i$ refers to the subject, $f()$ is an increasing function to be specified soon, $a_{i}$ and $b_{i}$ are subject-specific constants, and $e_{i}$ is experimental noise. A standard sigmoid corresponds to the case where $f$ is linear. Because $E C U$ is convex in $E C U^{T}$ for low values and concave for high values, this formulation models how experimental noise biases allocations away from the boundaries of $[0,100] .{ }^{24}$ The choice of $f()$ reflects behavior in the absence of noise. For instance, if $f(p)$ is finite at $p=0$, then the decision maker would be risk-loving because the allocation to

\footnotetext{
${ }^{21}$ Subjects make mistakes, get confused, or simply find it difficult to maintain the same level of engagement throughout the rounds of an experiment. There is also the possibility that they enjoy injecting a random component to their choices. Holding constant the subjective probability and treatment, the average filtered subject exhibited a standard deviation of 11 ECU in their allocations.

${ }^{22}$ While this bias can also impact the estimates in Table 2, within-subject estimates are more sensitive to the noise-induced bias. Indeed, consistent with a bias-driven deviation from the regression model, the residuals in Regression (2) of Table 2 exhibit a U-shape magnitude with respect to the perceived probability (roughly highest at the boundaries).

${ }^{23}$ A sigmoid function takes the form, $y=A(1+\exp (a-b x))^{-1}$ with $b \geq 0$.

24 This is an implication of Jensen's Inequality.
} 
the stock (an actuarially fair gamble at $p=0$ ) would be greater than zero. Because $b$ is a measure of the sensitivity of allocation to a first-degree stochastically dominating shift in the payoff distribution of the stock, one can interpret $b>0$ as a measure of local risk tolerance with higher $b$ signifying higher risk tolerance. We model

$$
f(p)=\ln \left(\frac{p}{1-p}\right)
$$

Our modeling choice implies global risk aversion and also that, absent noise, as subjective probability approaches one the allocation will tend to the full endowment of 100 ECU. This lends parsimony to modeling the dependence of allocation on subjective probability. ${ }^{25}$

To address the issue of statistical power, we adopt a random effects framework estimated to allow for treatment differences. That is, we allow each subject to have a different average level of investment (intercept, $a_{i}$ ) and a different allocation sensitivity to probabilities (slope, $b_{i}$ ) in each of the treatments. In a random effects framework, the subject-level coefficients are assumed to be drawn from a distribution whose mean and standard deviation are estimated. A benefit of this approach over individual regressions is the joint estimation of covariance of distinct random effects. The estimated model is

$$
E C U_{\tau, i, n}^{T}=a_{\tau, i}+b_{\tau, i} f\left(\operatorname{Prob}_{\tau, i, n}\right)+e_{\tau, i, n}
$$

where $\tau$ denotes the treatment, $i$, the subject ID (corresponding to the random effect), $n$, the round number for the given treatment, and $\operatorname{Prob}_{\tau, i, n}$, the probability reported by the subject in round $n$ of the given treatment.

\footnotetext{
${ }^{25}$ To avoid infinities in expressions (2) and (3), extreme allocations of 0 or 100 ECU are adjusted to 0.1 or 99.9 ECU, respectively, and extreme reported probabilities of 0 or 1 are adjusted to 0.001 or 0.999 . The qualitative conclusions of our analysis are robust to simply excluding these observations. They are also robust to alternative specifications such as, $f(p)=p$, or $f(p)=\ln (p)$, or $f(p)=c \ln (p)+d p$, or $f(p)=c \ln (p)+\ln (1-p)$.
} 
Results are reported in Table 3 and correspond to the estimated means, standard deviations, and correlations of the distribution of random coefficients. ${ }^{26}$ Table 3 also reports the residual standard deviation. Consistent with our prior results, we observe that in the Negative treatment, relative to the Neutral one, both the baseline allocation, mean $(a)$, and the sensitivity to probabilities, mean $(b)$, are significantly lower. By contrast, the two Positive treatment mean coefficients do not allow for a simple ranking relative to the Neutral treatment estimates (the joint difference is statistically insignificant with a $p$ value of $36 \%$ ).

Table 3: Random effects regression of transformed allocation on reported probabilities The table reports random-effect regressions of transformed allocations on reported probabilities estimated as specified in Equation (4). The error term is assumed to be i.i.d. across subjects and rounds, within treatment. Standard errors are in parentheses.

\begin{tabular}{lcccc} 
Treatment & $\operatorname{mean}(b)$ & $\operatorname{sd}(b)$ & $\operatorname{mean}(a)$ & $\operatorname{sd}(a)$ \\
\hline Negative & $0.652^{* * *}$ & $0.699^{* *}$ & $-1.733^{* * *}$ & $1.880^{* * *}$ \\
& $(0.082)$ & $(0.081)$ & $(0.177)$ & $(0.132)$ \\
Neutral & $0.966^{* * *}$ & $0.581^{* * *}$ & $-0.751^{* * *}$ & $1.651^{* * *}$ \\
& $(0.069)$ & $(0.073)$ & $(0.156)$ & $(0.117)$ \\
Positive & $0.903^{* * *}$ & $0.857^{* * *}$ & $-0.583^{* * *}$ & $1.690^{* * *}$ \\
& $(0.095)$ & $(0.087)$ & $(0.159)$ & $(0.119)$ \\
\hline \multirow{2}{*}{} & $\operatorname{sd}\left(e_{\text {Neg }}\right)$ & $\operatorname{sd}\left(e_{\text {Neu }}\right)$ & $\operatorname{sd}(e P o s)$ & $N$ \\
\hline & $1.904^{* * *}$ & $1.805^{* * *}$ & $1.684^{* * *}$ & 4500 \\
& $(0.038)$ & 0.036 & 0.034 & \\
\hline & & & Note: ${ }^{*} p<0.1 ; * * p<0.05 ; * * * p<0.01$
\end{tabular}

Second, the table shows that the slope dispersion across subjects, $\operatorname{sd}(b)$, is estimated to be larger in the Negative and Positive treatments, compared with the Neutral treatment. This suggests pronounced heterogeneity in treatment effects across subjects. Finally, we observe large and heterogeneous levels of residual variation across the treatments. The residual magnitudes justify our effort to adjust for edge-induced biases. ${ }^{27}$

\footnotetext{
${ }^{26}$ We only report significant random effect correlations.

27 The random effects model estimates correlations between the a's and b's, some of which are found to be statistically different from zero. In the interest of brevity, we omit these results.
} 
Figure 2 plots the estimated allocation using the mean coefficients from Table 3 and setting the experimental noise to zero. The plot includes 95\% confidence interval bars for the Positive and Negative treatments. ${ }^{28}$ From this figure we observe that the negative treatment effect is most pronounced when the subjective probability is higher than $50 \%$. The figure also confirms the absence of an average charitable giving motive which, if present, would imply a significantly higher allocation in the Positive treatment at low probabilities. As with Figure 1, the Positive treatment allocations are generally above those of the Neutral treatment, but we stress that the two Neutral and Positive treatment curves cannot be differentiated statistically because they are generated by coefficients that are (jointly) not statistically different.

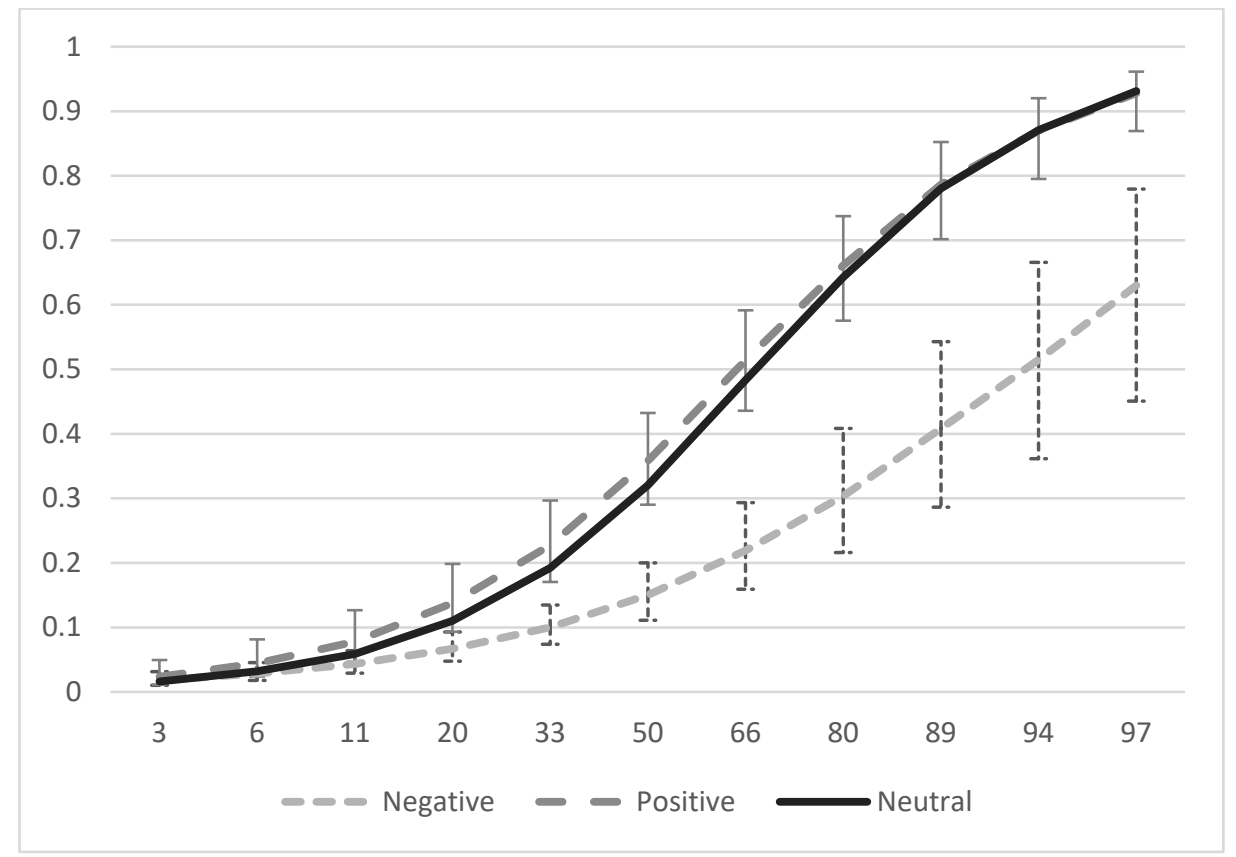

\section{Figure 2: Expected allocations across treatments}

This figure depicts estimated model predictions of the treatment effects on allocation (y-axis) against subjective probability that the stock is of high type (x-axis). The estimated model prediction sets experimental noise to zero. By contrast, Figure 1 is based on aggregated statistics that potentially include bias from experimental noise.

\footnotetext{
${ }^{28}$ The Neutral treatment confidence intervals, like the Neutral treatment point estimates, are close to those of the Positive treatment. We omit these for visual clarity.
} 
To compare model predictions to the simple statistics from Table 1, Panel A, we use the model estimates of each subject's intercept and slope parameters to calculate that subject's expected allocations in the treatment without experimental noise. We do this using the theoretical distribution of objective stock probabilities in the six rounds. ${ }^{29}$

Table 4 reports the average over subjects of their predicted expected allocation in each of the treatments. Consistent with the results of Table 1, the expected allocations are lower in the Negative treatment $(0.262)$ relative to the Neutral treatment $(0.373)$ which, in turn, is not far from the expected allocation in the Positive treatment (0.403). The magnitude of the treatment effect is similar to that documented in Table 1 and corresponds to a reduction of nearly $30 \%$ in allocations in going from the Neutral to the Negative treatment.

\section{Table 4: Average of expected allocations in each treatment}

The table reports the expected allocation averaged across subjects in each of the treatments based on subject-level coefficient estimates of the mixed regression in Equation (4) and assuming no experimental noise (the residual is set to zero).

\begin{tabular}{lccccc}
\hline Treatment & Obs & Mean & Std. Dev. & Min & Max \\
\hline Negative & 125 & 0.262 & 0.183 & 0.001 & 0.783 \\
Neutral & 125 & 0.373 & 0.205 & 0.015 & 0.996 \\
Positive & 125 & 0.403 & 0.206 & 0.021 & 0.998 \\
\hline
\end{tabular}

To examine the heterogeneity of the treatment effect across subjects, we compute for each subject the difference in expected allocation between the Negative and the Neutral treatments, and again the difference in expected allocation between the Positive and the Neutral treatments. This analysis allows us to compute two relative treatment effect measures per subject. We plot the distribution of these relative treatment effects in Figure 3. Under the null

\footnotetext{
${ }^{29}$ For example, using the binomial distribution, we calculate that the stock should objectively be deemed to have a $50 \%$ chance of being the high-paying type in $29 \%$ of the rounds: This is sure to be the case in all of the first rounds, in 4 of 9 instances of the third round, and in 24/81 instances of the fifth round (and in none of the second, fourth, and sixth rounds). Adding up and dividing by six possible rounds we get $(1+4 / 9+24 / 81) / 6=$ 0.29 .
} 
that differences in behavior across treatments are noise, the distribution of relative treatment effects should be symmetric about zero. The histograms in Figure 3 suggest that this roughly holds for the Positive treatment but that the same is not true for the Negative treatment.

\section{Figure 3: Distribution of allocations -- Histograms}

The figure reports the distribution of subjects' expected allocations in the two treatments relative to their expected allocation in the Neutral treatment. Expectations are calculated using subject-level coefficient estimates of the mixed regression in Equation (4) and assuming no experimental noise (the residual is set to zero).
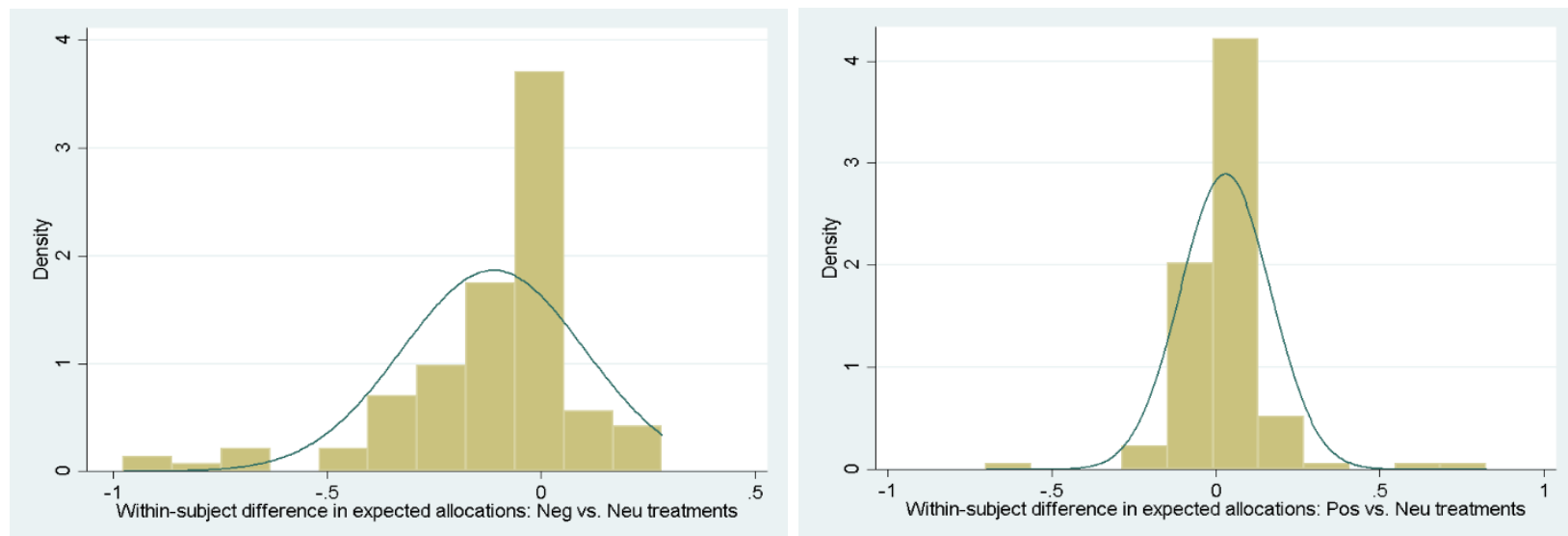

To quantify treatment-dependent heterogeneity across subjects, we estimate a 2component finite mixture model of normal distributions to each of the histograms. The results, reported in Table 5, suggest that the vast majority of subjects (just over 90\%) are drawn from a population that expects to allocate only two more ECUs in the Positive treatment (component 1) than in the Neutral treatment, while the remaining part of the population may allocate much more (14 ECUs) but their mean allocation is not statistically distinguishable from zero (component 2). By contrast, roughly half of subjects are drawn from a population that expects to allocate 20 ECUs less in the Negative treatment (relative to the Neutral treatment), while the remaining expect to allocate 3 ECU less. This analysis demonstrates that the treatment effect is not just strong in aggregate but also pervasive across subjects. The finding that roughly half of subjects are highly sensitive to the Negative treatment is consistent with the survey finding 
by Bauer et al. (2021) that two out of three Dutch pension plan participants were in favor of RI mandates.

\section{Table 5: Distribution of allocations: Finite-mixture model analysis}

The table reports a decomposition of each histogram in Figure 3 into a mixture of two normal distributions. Means, standard deviations, and mixture probability are estimated for the data depicted in each of the histograms.

\begin{tabular}{lcc}
\hline $\begin{array}{l}\text { Within-subject difference in expected allocations relative to } \\
\text { the Neutral treatment }\end{array}$ & \multicolumn{2}{l}{ Negative } \\
treatment & $\begin{array}{c}\text { Positive } \\
\text { treatment }\end{array}$ \\
\hline Mean of component 1 & $-0.0296^{* *}$ & $0.0211^{* *}$ \\
& $(0.009)$ & $(0.007)$ \\
Mean of component 2 & $-0.195^{* * *}$ & 0.12 \\
& $(0.039)$ & $(0.144)$ \\
SD of component 1 & $0.0500^{* * *}$ & $0.0687^{* * *}$ \\
& $(0.009)$ & $(0.009)$ \\
SD of component 2 & $0.274^{* * *}$ & $0.404^{* *}$ \\
& $(0.027)$ & $(0.122)$ \\
\hline & & \\
\hline Probability of component 1 & 0.505 & $0.916^{* * *}$ \\
& $(0.074)$ & $(0.052)$ \\
\hline $\mathrm{N}$ & 125 & 125 \\
\hline & Note: ${ }^{*} p<0.1 ;{ }^{* *} p<0.05 ;{ }^{* * *} p<0.01$
\end{tabular}

Finally, to obtain further confirmation that a Negative treatment effect is pervasive among participants, we plot the expected allocation in the Negative treatment against the Positive treatment, by subject, and relative to a 45-degree line (see Figure 4). First, the figure shows that most subjects fall under the 45-degree line, consistent with allocations in the Negative treatment being lower than in the Positive treatment, even when accounting for differences in baseline levels of allocations. Second, the asymmetry in distribution relative to the 45-degree line is observed for virtually all levels of Positive treatment allocations. Thus, the sensitivity to negative externalities is found among all subjects - those that appear to care about positive externalities and those that do not. 


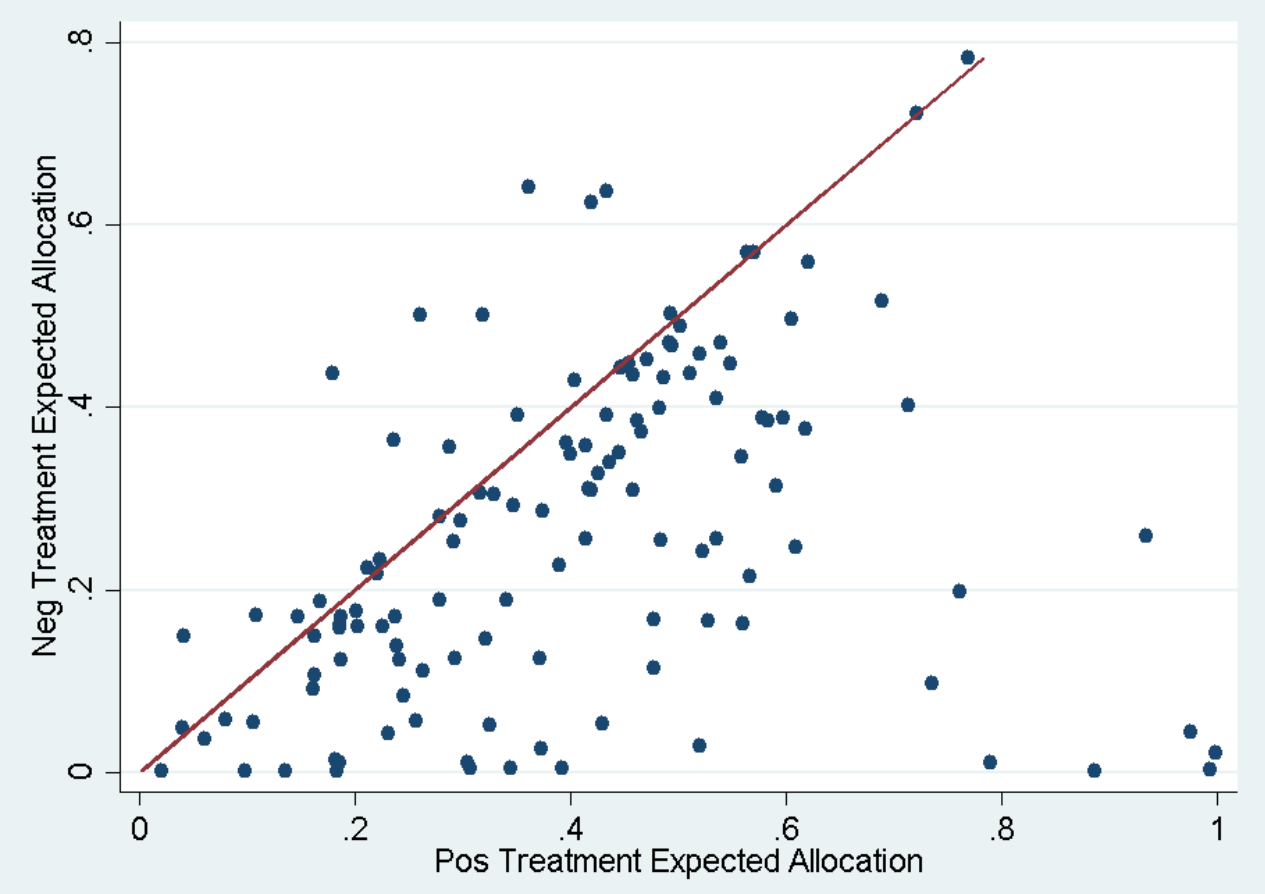

\section{Figure 4: Expected allocations in positive and negative treatments}

The figure reports the expected allocations in the Positive and Negative treatments based on model estimates (see Table 3). Each dot corresponds to a subject.

\subsection{Probability estimates}

We now turn to assessing the effect externalities have on subjective probability estimates. The histogram in Figure 5 compares true (objective) versus subjective (reported) probabilities for various true probability bins. The Bayesian objective probability of the stock being of the high return type is calculated as follows: given a history of $n$ doubling and $m$ halving outcomes, it is $2^{n-m} /\left(2^{n-m}+1\right)$. Given the discrete nature of signals and the asymmetry of updating, in most rounds, the true probability will be one of $1 / 3,1 / 2$, and 2/3 (corresponding to $|n-m| \leq$ 1). We therefore use five true probability bins: below $1 / 3$, exactly $1 / 3$, exactly $1 / 2$, exactly $2 / 3$, and above 2/3. The thick black bars indicate the expected true probability for the corresponding bin (exactly $1 / 3,1 / 2$, or $2 / 3$ for the inner bins, and the expected value of the true probabilities in the outer bins). The bars depict the subjective probability for the different treatments. 


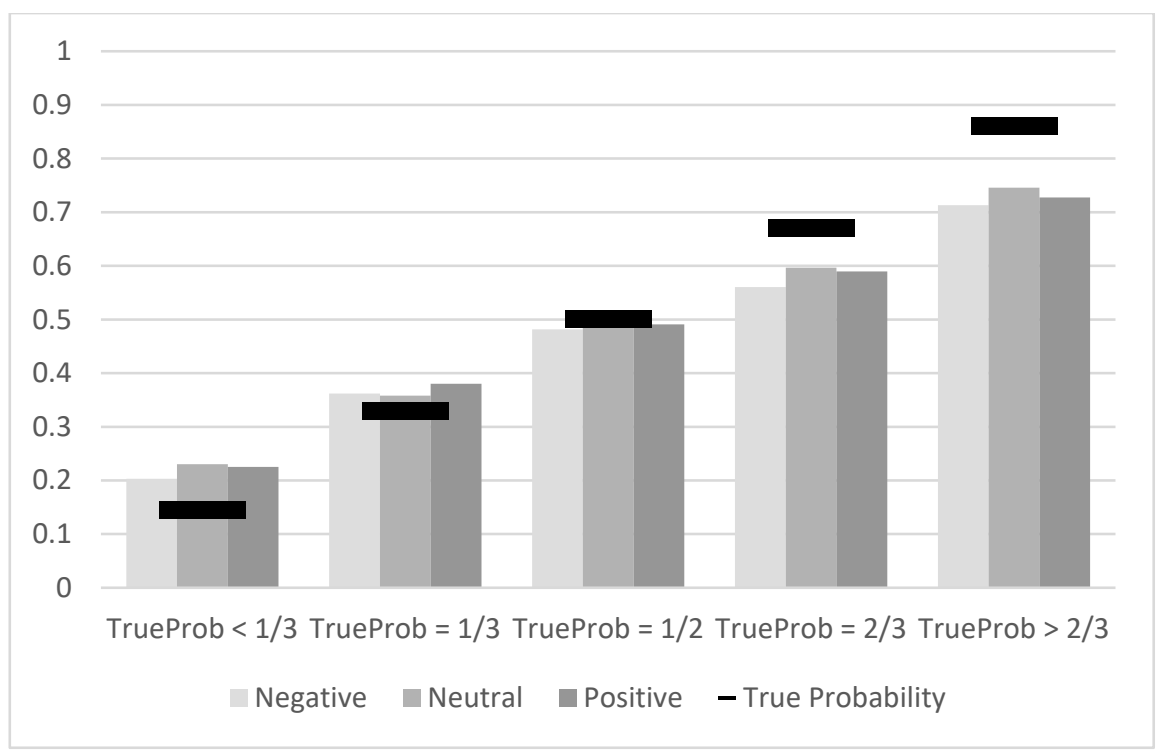

Figure 5: Objective and subjective probabilities

This figure maps objective probabilities of the stock's type to subjective probabilities. The thick black bars indicate the expected true probability for the corresponding bin (exactly $1 / 3,1 / 2$, or $2 / 3$ for the inner bins, and the expected value of the true probabilities in the outer bins). The bars depict the subjective (reported) probability for the different treatments.

A couple of patterns emerge in Figure 5. First, consistent with a large prior literature (e.g., Tversky and Kahneman, 1992, Abdellaoui, et. al., 2011, and Kuhnen, 2015), we find that subjective probabilities are "shrunk" toward the unconditional prior of $1 / 2$. That is, when objective probabilities are less (more) than 1/2, subjects' perception of probabilities are too high (low). Second, we find that subjective probabilities in the Negative condition tend to be lower than the probabilities in the Positive condition. This difference is around 0.2 percentage points for both high and low objective probabilities.

The first pattern noted above resembles the behavior of "subjective weights" in nonexpected utility models, such as Cumulative Prospect Theory. In particular, Prelec (1998) suggests the following two-parameter description:

$$
\text { Subjective weight }=\exp \left(-\delta *(-\log (\text { True Prob }))^{\gamma}\right) \text {. }
$$

Over the range of observations, we can roughly think of $\delta$ as a level parameter, shifting subjective probabilities up or down relative to objective probabilities, and of $\gamma$ as a curvature 
parameter. We adopt this formulation and fit our data to it using treatment dummies. That is, we allow both $\delta$ and $\gamma$ to vary with the treatment.

With the baseline being the Negative treatment, we report in Figure 6 that the additional shift away from objective probabilities in both the Neutral and Positive treatments is statistically significant ( $\delta_{\mathrm{Neu}}$ and $\delta_{\mathrm{P} \text { os }}$ are statistically different from zero). We find no treatment effect for the curvature of the function ( $\gamma_{\text {Neu }}$ and $\gamma_{\text {Pos }}$ are not statistically different from zero).

\begin{tabular}{cc}
\hline Variable & Estimate \\
\hline$\delta_{\text {Neg }}$ & 0.974 \\
& $(0.012)$ \\
$\gamma_{\text {Neg }}$ & 0.604 \\
& $(0.0167)$ \\
$\delta_{\text {Neu }}$ & -0.0484 \\
& $(0.0164)$ \\
$\delta_{\text {Pos }}$ & -0.0462 \\
& $(0.0164)$ \\
$\gamma_{\text {Neu }}$ & 0.0019 \\
& $(0.0236)$ \\
$\gamma_{\text {Pos }}$ & 0.0287 \\
& $(0.024)$ \\
\hline
\end{tabular}

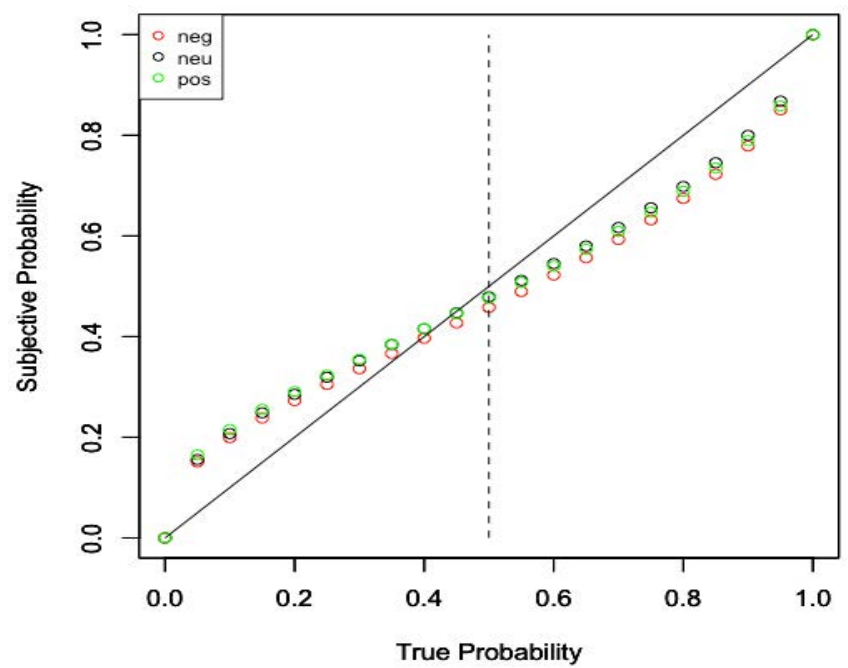

\section{Figure 6: Cumulative probability function}

This figure shows the maximum-likelihood estimation of equation (1) along with a plot that depicts the estimated parameters. Standard errors are in parentheses.

In Figure 6, we also plot the fitted treatment-dependent subjective probability as a function of objective probabilities. Subjective probabilities in the Positive and Neutral treatments are very close together, while those of the Negative treatment are consistently below, across the entire range of objective probabilities. The shift down, in the Negative treatment, appears to be similar across the range, consistent with the treatment effect on curvature being insignificant. 


\subsection{Learning}

To further understand how considerations of externalities distort beliefs, we turn to examining how subjects learn in the experiment. Because probability estimates are submitted after observing realization of payoffs from the stock investment, we can investigate whether, and how, the treatments affect learning.

An extensive literature studies experimentally and theoretically how learning in various settings deviates systematically from the Bayesian framework (e.g., Tversky, 1973; Slovic and Lichtenstein, 1971; Svenson, 1981). We build on earlier work that nests two important deviations from Bayesian updating in a simple linear framework (Mobius et al., 2011) by transforming priors and posteriors into log odds. The nested deviations include asymmetric updating (responding differently to positive and negative signals) and conservatism (interpreting signals as less informative than they are). Specifically, we estimate the following linear regression:

$$
\operatorname{logit}\left(\mu_{i, t}\right)=\operatorname{\delta logit}\left(\mu_{i, t-1}\right)+\beta_{H} I\left(S_{i, t}=H\right) \lambda_{H}+\beta_{L} I\left(S_{i, t}=L\right) \lambda_{L}+\varepsilon_{i, t}
$$

Where $\mu_{i, t}$ is the reported probability by subject $i$ in period $t, \operatorname{logit}(x)=\ln \left(x /(1-x), \lambda_{H}=\right.$ $\ln (2)$ is the log odds of the probability that the stock is of the "High" type, $\lambda_{H}=-\ln (2)$ is the log odds of the probability that the stock is of the "Low" type, $I\left(S_{i, t}=H\right)$ is an indicator function for a round in which the stock doubles, and $I\left(S_{i, t}=L\right)$ is an indicator function for a round in which the stock halves. It is straightforward to check that the Bayesian case corresponds to setting where $\beta_{H}=\beta_{L}=1$. Any difference between $\beta_{H}$ and $\beta_{L}$ implies an asymmetry in updating with respect to positive versus negative information about the stock's performance. Deviation of the coefficients from one corresponds to subjects' under- or overreaction to information. 
We estimate this regression for each treatment separately while clustering standard errors by subject. The regression results are presented in Table 6, panel A. Consistent with Mobius et al. (2011), we find that subjects generally tend to underweight new information when updating, as compared with the Bayesian predictions (panels A and B). In the Neutral treatment, there does not appear to be asymmetry in underweighting positive versus negative new information about the stock. This contrasts with the results in Mobius et al. (2011), potentially because subjects are not as emotionally linked to whether the information is positive or negative aside from the bet they are making. ${ }^{30}$ Consistent with the hypothesis that the Positive and Negative treatments influence subjects’ emotional connection to stock outcomes, panel C presents evidence of asymmetry in the Positive and (especially) Negative treatments. In both cases, positive information about the stock type is discounted relative to negative news. However, the asymmetry is much more pronounced in the Negative treatment.

When we test for treatment effects, comparing the Neutral treatment to both the Positive and Negative ones, we find interesting results. First, there does not appear to be a statistically significant difference between the Neutral and Positive treatments. Second, the only significant difference that we find between the Neutral and Negative treatments is observed with respect to the response to positive information. Namely, subjects respond less to positive information in the Negative treatment relative to Neutral one. This aligns with our observations about the role of the Negative treatment in distorting perceptions of outcomes: The Positive and Neutral treatments are nearly indistinguishable, while the Negative and Neutral treatments differ significantly.

While the results on the asymmetry in updating in the Negative treatment are intriguing, their economic magnitude is rather small. This is consistent with the overall pattern observed in the study where belief distortion plays a secondary role when compared to the treatment

\footnotetext{
${ }^{30}$ In Mobius et al. (2011), the information conveys personal information in that it is about a subject's IQ.
} 
effects on risk attitudes. To quantify this, we use the estimated coefficients to compute the posterior probability of the average subject in the Negative relative to the Neutral treatments after observing a sequence of five positive signals or a sequence of five negative signals. We find that after a sequence of five positive signals, subjects in the Negative treatment are predicted to report a probability of $83.4 \%$, relative to $86.7 \%$ in the Neutral one: A $3.3 \%$ decline in reported probability. The difference after a sequence of five negative signals is only $1.8 \%$ (10.6\% relative to $12.4 \%)$.

\section{Table 6: Learning across treatments}

The table reports the regression results corresponding to Eq. (6), in which sequential learning is allowed to deviate from the Bayesian null both a base-rate neglect as well as asymmetry in response to negative and positive information. The model is estimated separately for each treatment cell (Panel A); test of coefficients' deviations from the Bayesian null are tested (Panel B); differences in estimated coefficients across treatments are tested (Panel C).

Panel A: Expected average allocations

\begin{tabular}{llll}
\hline & $(1)$ & $(2)$ & $(3)$ \\
\hline Variables & Neutral & Positive & Negative \\
$\delta$ & $0.889^{* * *}$ & $0.905^{* * *}$ & $0.956^{* * *}$ \\
& $(0.03)$ & $(0.04)$ & $(0.04)$ \\
$\beta_{H}$ & $0.674^{* * *}$ & $0.591^{* * *}$ & $0.508^{* * *}$ \\
& $(0.04)$ & $(0.04)$ & $(0.04)$ \\
$\beta_{L}$ & $0.704^{* * *}$ & $0.708^{* * *}$ & $0.672^{* * *}$ \\
& $(0.05)$ & $(0.04)$ & $(0.04)$ \\
Observations & 1,159 & 1,169 & 1,125 \\
R-squared & 0.68 & 0.73 & 0.76 \\
& & & \\
\hline
\end{tabular}


Panel B: Testing the Bayesian Predictions

\begin{tabular}{llll}
\hline (p-values) & $(1)$ & $(2)$ & $(3)$ \\
\hline Test & Neutral & Positive & Negative \\
$\operatorname{Prob}(\delta==1)$ & 0.00 & 0.01 & 0.23 \\
$\operatorname{Prob}\left(\beta_{H}==1\right)$ & 0.00 & 0.00 & 0.00 \\
$\operatorname{Prob}\left(\beta_{L}==1\right)$ & 0.00 & 0.00 & 0.00 \\
$\operatorname{Prob}\left(\beta_{H}==\beta_{L}\right)$ & 0.5723 & 0.0113 & 0.0011 \\
& & & \\
\hline
\end{tabular}

Panel C: Testing for treatment effect

\begin{tabular}{lll}
\hline (p-values) & $(2)$ & $(3)$ \\
\hline Test & Neutral==Positive & Neutral==Negative \\
$\delta$ & 0.6991 & 0.1734 \\
$\beta_{H}$ & 0.0604 & 0.0006 \\
$\beta_{L}$ & 0.9295 & 0.4391
\end{tabular}

\section{Conclusions}

In this paper we employ an experimental setting to study how social preferences influence individuals' investment decisions. We find that these preferences regarding responsible investing affect individuals' choices on allocations between a risky asset and cash as well as their subjective investment beliefs. Adapting the Kuhnen (2015) experimental design to focus on the effects of social preferences, our study participants confront a question of allocating funds between investments in a risky stock investment and a risk-free investment (cash) when their investment choices affect payments made to a nonprofit they select. The experimental treatments serve to either align or drive a wedge between subjects' social preferences and their personal investment returns.

Our experimental findings suggest that the social externalities have a strong but asymmetric impact on investor risk attitudes. The participants' asset allocation decisions indicate that investors are much more inclined to avoid the negative externalities of their investments than they are to embrace the positive externalities. Interestingly, evidence of 
charitable-giving motives appears to be largely absent in the data. The effect we find is not high in magnitude, but also pervasive among a large portion of the subject pool. This suggests that, based on existing theoretical work, when extrapolated to a market setting our findings would translate into observable price impacts, but only for firms associated with negative externalities. Indeed, a survey of the empirical RI literature would suggest not only a prevalence of negative screening - an important component of the majority of RI strategies but that only "sin stocks" consistently exhibit greater discounting than warranted based on conventional risk adjustment (evidence for the overpricing of "angel stocks" tends to be mixed). Another of our novel experimental findings is that social preferences affect investors' subjective probabilities about their investments. Although this latter effect is modest, it reflects the importance that social preferences can have on how investors process information (e.g., update their beliefs).

Responsible investing has become an increasingly important aspect of individuals’ investment opportunity sets. Theory and empirical evidence demonstrated that growing tastes for responsible investing can impact asset pricing. Our findings help refine existing facts and insights by pointing to novel drivers of responsible investment. Importantly, our results have implications for how to think about incorporating social preferences into existing models because they demonstrate not only how utility is affected but also the large heterogeneity that exists in these effects. In addition, our results have implications for policy. In particular, the strong asymmetric effects we find suggest that, from investors' perspective, the marginal benefit of reducing harm is much greater than the marginal benefit of doing good. 


\section{References}

Abdellaoui, M., A. Baillon, L. Placido, and P. Wakker, 2011. The rich domain of uncertainty: Source functions and their experimental implementation, American Economic Review 101, 695-723.

Albuquerque, R., Y. Koskinen, and C. Zhang, 2019. Corporate social responsibility and firm risk: Theory and empirical evidence. Management Science 65, 4451-4469.

Baker, S.D., B.Hollifield, and E. Osambela. 2020. Asset prices and portfolios with externalities. Unpublished working paper.

Barber, B., A. Morse, and A. Yasuda. 2021. Impact investing. Journal of Financial Economics, 139, 162-185.

Baron, D. P. 2007. Corporate social responsibility and social entrepreneurship. Journal of Economics \& Management Strategy 16, 683-717.

Baron, D. P. 2008. Managerial contracting and corporate social responsibility. Journal of Public Economics 92, 268-288.

Bauer, R., T. Ruof, and P. Smeets (2021. Get real! Individuals prefer more sustainable investments. Review of Financial Studies 34, 3976-4043.

Benabou, R. and J. Tirole. 2010. Individual and corporate social responsibility. Economica 77, 1-19.

Benson, K. L. and J. E. Humphrey. 2008. Socially responsible investment funds: Investor reaction to current and past returns. Journal of Banking and Finance 32, 1850-1859.

Bialkowski, J. and L. T. Starks. 2018. SRI funds: Investor demand, exogenous shocks and ESG profiles. Unpublished working paper.

Bollen, N. 2007. Mutual fund attributes and investor behavior. Journal of Financial and Quantitative Analysis 42, 689-708.

Bolton, P. and M. T. Kacperczyk. 2021. Do investors care about carbon risk? Journal of Financial Economics, forthcoming.

Bonnefon, J., A. Landier, P. Sastry, and D. Thesmar. 2019. Do investors care about corporate externalities? Experimental evidence. HEC Paris Research Paper No. FIN-20191350 .

Brodback, D., N. Guenster and D. Mezger. 2019. Altruism and egoism in investment decisions. Review of Financial Economics 37, 118-148.

Brodback, D., N. Guenster and S. Pouget. 2020. The valuation of corporate social responsibility: A willingness-to-pay experiment. Unpublished working paper. 
Chava, S. 2014. Environmental externalities and cost of capital. Management science 60, 2223-2247.

Chew, S. H., and K. K. Li. 2021. The moral investor: Sin stock aversion and virtue stock affinity. Available at SSRN 3773971.

Chowdhry, B., S. W. Davies and B. Waters. 2019. Investing for impact. Review of Financial Studies 32, 864-904.

Cooper, D. J., and J. Kagel. 2016. Other-regarding preferences. The Handbook of Experimental Economics 2, 217-289.

Dimson, E., Karakaş, O.,Li, X. 2015. Active ownership. Review of Financial Studies 28, 3225-3268.

Dimson, E., Karakaş, O.,Li, X. 2021. Coordinated engagements. Unpublished working paper.

Edmans, A. 2011. Does the stock market fully value intangibles? employee satisfaction and equity prices. Journal of Financial Economics 101, 621-640.

Engel, C. 2011. Dictator games: A meta study. Experimental economics 14, 583-610.

Fabozzi, F., K. Ma and J. Oliphant. 2008. Sin stock returns. Journal of Portfolio Management 35, 82-94.

Fama E., and K. French. 2007. Disagreement, tastes and asset prices. Journal of Financial Economics 83 667-689.

Flammer, C. (2021) Corporate green bonds. Journal of Financial Economics, forthcoming.

Friede, G., T. Busch, and A. Bassen. 2015. ESG and financial performance: Aggregated evidence from more than 2000 empirical studies. Journal of Sustainable Finance and Investment 5, 210-233.

Geczy, C., J. S. Jeffers, D. K. Musto and A. M. Tucker. 2021. Contracts with (social) benefits: The Implementation of impact investing. Journal of Financial Economics, forthcoming.

Geczy, C. C., R.F. Stambaugh, and D. Levin. 2021. Investing in socially responsible mutual funds, The Review of Asset Pricing Studies 11, 309-351..

Goldstein, I., A. Kopytov, L. Shen, H. Xiang. 2021. On ESG investing: Heterogeneous preferences, information and asset prices. Unpublished working paper.

Guerard, J. 1997. Is there a cost to being socially responsible? Journal of Forecasting 16, 475-490.

Hamilton, S., H. Jo and M. Statman. 1993. Doing well by doing good? The investment performance of socially responsible mutual funds. Financial Analysts Journal 49 62-66. 
Hartzmark, S. M. and A. B. Sussman. 2019. Do investors value sustainability? A natural experiment examining ranking and fund flows. Journal of Finance, 74, 2789-2837.

Heeb, F., J. Kölbel, F. Paetzold, and S. Zeisberger. 2021. Do investors care about impact? Unpublished working paper.

Heinkel, R., A. Kraus, and J. Zechner. 2001. The effect of green investment on corporate behavior. Journal of Financial and Quantitative Analysis 36, 431-449.

Hoepner, A. G. F., I. Oikonomou, Z. Sautner, L. T. Starks, and X. Y. Zhou. 2021. ESG shareholder engagement and downside risk. Unpublished working paper.

Hong, H. and M. Kacperczyk. 2009. The price of sin: The effects of social norms on markets. Journal of Financial Economics 93, 15-36.

Humphrey, J. E., D. D. Lee, and Y. Shen. 2012. Does it cost to be sustainable? Journal of Corporate Finance 18, 626-639.

Kahneman, D., and A. Tversky. 1979. Prospect theory: An analysis of decision under risk. Econometrica, 47, 263-291.

Kuhnen, C. 2015. Asymmetric learning from financial information. Journal of Finance 70, 2029-2062.

Krueger, P. 2015. Corporate goodness and shareholder wealth. Journal of Financial Economics 115, 304-329.

Krueger, P., Z. Sautner, and L. Starks. 2020. The importance of climate risk for institutional investors. Review of Financial Studies 33, 1067-1111.

Larcker, D.F. and E.M. Watts. 2020. Where's the greenium? Journal of Accounting and Economics 69, Article 101312.

Lins, K. V., H. Servaes, and A. Tamayo. 2017. Social capital, trust, and firm performance: The value of corporate social responsibility during the financial crisis. Journal of Finance 72, 1785-1824.

List, J. 2007. On the interpretation of giving in dictator games. Journal of Political Economy 115), 482-493.

Luo, H. and Balvers, R. 2017. Social screens and systematic investor boycott risk. Journal of Financial and Quantitative Analysis 52, 365-399.

Mobius, M. M., Niederle, M., Niehaus, P. and Rosenblat, T. S. 2011. Managing selfconfidence: Theory and experimental evidence. National Bureau of Economic Research (No. w17014).

Oehmke, M., and M. Opp. 2020. A theory of socially responsible investment. Unpublished working paper. 
Pastor, L., R. Stambaugh, and L. Taylor. 2021. Sustainable investing in equilibrium. Journal of Financial Economics, forthcoming.

Pedersen, Lasse Heje, Shaun Fitzgibbons, and Lukasz Pomorski. 2021. Responsible investing: The ESG-efficient frontier. Journal of Financial Economics, forthcoming.

Prelec, D. 1998. The probability weighting function. Econometrica 66, 497-528.

Renneboog, L., J. ter Horst, and C. Zhang. 2008a. The price of ethics and stakeholder governance: The performance of socially responsible mutual funds. Journal of Corporate Finance 14, 302-322.

Renneboog, L., J. Ter Horst, and C. Zhang. 2008b. Socially responsible investments: Institutional aspects, performance, and investor behavior. Journal of Banking and Finance 32, 1723-1742.

Riedl, A. and P. Smeets. 2017. Why do investors hold socially responsible mutual funds? Journal of Finance 72, 2505-2550.

Scheinkman, J. A., and W. Xiong. 2003. Overconfidence and speculative bubbles. Journal of Political Economy 111, 1183-1220.

Slovic, P., and Lichtenstein, S. 1971. Comparison of Bayesian and regression approaches to the study of information processing in judgment. Organizational behavior and human performance, 6(6), 649-744.

Starmer, C. 2000. Developments in non-expected utility theory: The hunt for a descriptive theory of choice under risk. Journal of Economic Literature 38, 332-382.

Statman, M., and D. Glushkov. 2009. The wages of social responsibility. Financial Analysts Journal 65, 33-46.

Stroebel, J., and J. Wurgler. 2021. What do you think about climate finance? Journal of Financial Economics, forthcoming.

Svenson, O. 1981. Are we all less risky and more skillful than our fellow drivers?. Acta psychologica, 47(2), 143-148.

Tversky, A. 1973. On the psychology of prediction. Psychological Review, 80(4), 237-251.

Tversky, A., and D. Kahneman. 1992. Advances in prospect theory: Cumulative representation of uncertainty. Journal of Risk and Uncertainty 5, 297-323.

US SIF. 2020 Report on US sustainable, responsible and impact investing trends 2020. Washington, DC: US SIF. 


\section{Appendix: Experiment Snapshots}

\section{Panel A: Initial round allocation screen}

First Block, Trial One

You are about to begin a new trial consisting of six investing rounds.

The computer will now randomly select the type of stock you will be facing during this trial.

There is a $\mathbf{5 0} \%$ chance that the computer will select a high payoff stock and a $50 \%$ that it will select a low payoff stock.

A high payoff doubles with probability $2 / 3$ and halves with probability $1 / 3$.

A low payoff stock doubles with probability $1 / 3$ and halves with probability $2 / 3$.

Estimate the probability that this is the high payoff stock.

Please enter a number between 0 and 100:

You have $100 \mathrm{ECU}$. Enter the amount you wish to invest in the stock in the next round. The rest will be invested in risk-free cash.

Stock: 
Panel B: Outcome screen after three rounds

Trial: 1

The stock outcome for Round 3 is: Halve ( $\downarrow)$

History of Decisions and Outcomes

\begin{tabular}{|c|c|c|c|c|}
\hline $\begin{array}{c}\text { Round } \\
\text { Number }\end{array}$ & $\begin{array}{c}\text { Probability } \\
\text { Estimate Prior to } \\
\text { Outcome }\end{array}$ & $\begin{array}{c}\text { Stock Allocation } \\
\text { Prior to Outcome }\end{array}$ & Outcome & $\begin{array}{c}\text { Winnings } \\
\text { from } \\
\text { Round }\end{array}$ \\
\hline 1 & 20 & 50 & Halve $(\downarrow)$ & 75 \\
\hline 2 & 30 & 50 & Double \\
$(\uparrow)$ & 150 \\
\hline 3 & 40 & 40 & Halve $(\downarrow)$ & 80 \\
\hline 4 & & & & \\
\hline 6 & & & & \\
\hline
\end{tabular}

Recall that high payoff stocks will double with a probability of $2 / 3$ and halve with a probability of $1 / 3$.

Low payoff stocks will double with a probability of $1 / 3$ and halve with a probability of $2 / 3$.

Estimate the probability that this is the high payoff stock.

Please enter a number between 0 and 100:

You have $100 \mathrm{ECU}$. Enter the amount you wish to invest in the stock in the next round. The rest will be invested in risk-free cash.

Stock: 


\section{Panel C: Social issues}

\section{What Social Issues Are Important to You?}

Below are a number of current corporate social issues, listed in alphabetical order. Please rank these issues from 1 to 6 in terms of how much you care about each issue. A ranking of 1 means you care the most and a ranking of 6 means you care the least. You can rank by clicking and dragging. If you would like to keep the current ranking simply click and slightly drag any of the options.

Gender discrimination (example: not hiring women for jobs for which they are qualified)

Human Trafficking (example: forcing children to work as slave labour in factories or on farms)

Refugees (example: trading with dictatorial regimes which have resulted in mass fleeing from the country)

Poverty (example: underpaying workers in developing countries)

Animal welfare (example: infecting laboratory monkeys with diseases to test pharmaceutical drugs)

Environment (example: releasing carbon dioxide into the atmosphere)

\section{What Social Issues Are Important to You?}

You selected environment as your top social issue. Below is a description of two environmental non-profits.

The Rainforest Alliance works to conserve biodiversity and ensure sustainable livelihoods by transforming land-use practices, business practices and consumer behaviour.

Conservation Strategy Fund sustains natural ecosystems and human communities through strategies powered by conservation economics. Our trainings, analyses and timely expertise make development smarter, quantify the benefits of nature, and create enduring incentives for conservation.

Please select a non-profit organization to link to your trading profits:

The Rainforest Alliance

The Conservation Strategy Fund 


\section{Panel D: Positive block instruction screen and outcome screen}

The Conservation Strategy Fund gains by your stock investment

You are about to begin a block of two trials. Each trial consists of six investment rounds.

You will be asked to make the same decision as in the practice trial.

At the beginning of each of the two trials the computer will randomly choose whether the stock for that trial is a high or low payoff stock. You will then face the series of six investment rounds.

In each investment round you will be asked how much you wish to allocate to the stock and to cash. After the stock outcome is determined, you will be asked to indicate the probability that you are facing a high payoff stock and how much you trust your probability estimate.

One round may be randomly chosen as your actual payoff round. If that round is chosen as your payoff round, in addition to paying you, the researchers will DONATE the same amount of money as your payoff from your stock investment to your designated nonprofit. For example, if you earn $135 \mathrm{ECU}$ from investing including $70 \mathrm{ECU}$ from your stock investment, your chosen non-profit will receive $70 \mathrm{ECU}$.

The payment to the non-profit will come out of the researchers' funding, not from your trading payoff. You will be sent an email documenting our payments to the various non-profit organizations involved in this experiment in a few days.

Your designated non-profit for this block of three trials is: The Conservation Strategy Fund 
Non-profit gains by your stock investment

Trial: 1

The stock outcome for Round 3 is: Double $(\uparrow)$

\begin{tabular}{|c|c|c|c|c|c|}
\hline \multicolumn{6}{|c|}{ History of Decisions and Outcomes } \\
\hline $\begin{array}{l}\text { Round } \\
\text { Number }\end{array}$ & $\begin{array}{l}\text { Probability } \\
\text { Estimate } \\
\text { Prior to } \\
\text { Outcome }\end{array}$ & $\begin{array}{c}\text { Stock } \\
\text { Allocation } \\
\text { Prior to } \\
\text { Outcome }\end{array}$ & Outcome & $\begin{array}{l}\text { Winnings } \\
\text { from } \\
\text { Round (if } \\
\text { round is } \\
\text { selected) }\end{array}$ & $\begin{array}{c}\text { Payment to } \\
\text { The } \\
\text { Conservation } \\
\text { Strategy } \\
\text { Fund (if } \\
\text { round is } \\
\text { selected) }\end{array}$ \\
\hline 1 & 40 & 60 & $\begin{array}{c}\text { Double } \\
(\uparrow)\end{array}$ & 160 & 120 \\
\hline 2 & 60 & 45 & Halve $(\downarrow)$ & 77.5 & 22.5 \\
\hline 3 & 50 & 50 & $\begin{array}{c}\text { Double } \\
(\uparrow)\end{array}$ & 150 & 100 \\
\hline 4 & & & & & \\
\hline 5 & & & & & \\
\hline 6 & & & & & \\
\hline
\end{tabular}

Recall that high payoff stocks will double with a probsbility of $2 / 3$ and halve with a probability of $1 / 3$.

Low payoff stocks will double with a probability of $1 / 3$ and halve with a probability of $2 / 3$.

Estimate the probability that this is the high payoff stock.

Please enter a number between 0 and 100 :

You have $100 \mathrm{ECU}$. Enter the amount you wish to invest in the stock in the next round. The rest will be invested in risk-free cash.

Stock: 


\section{Panel E: Negative block instruction screen and outcome screen}

Block: SPCA International loses by your stock investment

You are about to begin a block of two trials. Each trial consists of six investment rounds.

You will be asked to make the same decision as in the practice trial.

At the beginning of each of the two trials the computer will randomly choose whether the stock for that trial is a high or low payoff stock. You will then face the series of six investment rounds.

In each investment round you will be asked how much you wish to allocate to the stock and to cash. After the stock outcome is determined, you will be asked to indicate the probability that you are facing a high payoff stock and how much you trust your probability estimate.

One round may be randomly chosen as your actual payoff round. If that round is chosen as your payoff round, in addition to paying you, the researchers will DEDUCT from funds allocated to the non-profit the same amount of money as your payoff from your stock investment. For example, if you earn $135 \mathrm{ECU}$ from investing including $70 \mathrm{ECU}$ from your stock investment, your chosen non-profit will have 70 ECU deducted from their balance.

The deduction from the non-profit will have no effect on your trading payoff. You will be sent an email documenting our payments to the various non-profit organizations involved in this experiment in a few days.

Your designated non-profit for this block of three trials is: SPCA International 
Block: Non-profit loses by your stock investment

Trial: 1

The stock outcome for Round 3 is: Double $(\uparrow)$

History of Decisions and Outcomes

\begin{tabular}{|c|c|c|c|c|c|}
\hline $\begin{array}{c}\text { Round } \\
\text { Number }\end{array}$ & $\begin{array}{c}\text { Probability } \\
\text { Estimate } \\
\text { Prior to } \\
\text { Outcome }\end{array}$ & $\begin{array}{c}\text { Stock } \\
\text { Allocation } \\
\text { Prior to } \\
\text { Outcome }\end{array}$ & Outcome & $\begin{array}{c}\text { Winnings } \\
\text { from } \\
\text { Round (if } \\
\text { this } \\
\text { round is } \\
\text { selected }\end{array}$ & $\begin{array}{c}\text { Deduction } \\
\text { from SPCA } \\
\text { International } \\
\text { (if this } \\
\text { round is } \\
\text { selected) }\end{array}$ \\
\hline $\mathbf{1}$ & 50 & 30 & Halve $(\downarrow)$ & 85 & -15 \\
\hline $\mathbf{2}$ & 20 & 40 & Halve $(\downarrow)$ & 80 & -20 \\
\hline $\mathbf{3}$ & 15 & 30 & Double & & \\
\hline $\mathbf{5}$ & & & & & \\
\hline
\end{tabular}

Recall that high payoff stocks will double with a probability of $2 / 3$ and halve with a probability of $1 / 3$.

Low payoff stocks will double with a probability of $1 / 3$ and halve with a probability of $2 / 3$.

Estimate the probability that this is the high payoff stock.

Please enter a number between 0 and 100 :

You have $100 \mathrm{ECU}$. Enter the amount you wish to invest in the stock in the next round. The rest will be invested in risk-free cash.

Stock: 